\title{
Simplificando a obtenção e a utilização de imagens digitais - scanners e câmeras digitais
}

\author{
André Wilson MACHADO*, Bernardo Quiroga SOUKI**
}

\begin{abstract}
Resumo
Um dos grandes benefícios que a evolução tecnológica proporcionou à Ortodontia foi a utilização das imagens digitais. $\mathrm{O}$ uso dessa nova tecnologia em Odontologia, e especificamente em Ortodontia, aliada à introdução da Fotografia Digital, permite aos profissionais desta área utilizar recursos, antes inimagináveis, facilitando a elaboração do diagnóstico ortodôntico, auxiliando a comunicação entre profissionais, bem como com os pacientes, além de ilustrar comunicações científicas, em conferências, cursos e publicações, sendo uma excelente ferramenta para o ensino e pesquisa. Com o objetivo de lançar mão dessa nova tecnologia, o ortodontista pode obter imagens digitais por meio da digitalização da documentação ortodôntica convencional composta basicamente de fotografias analógicas (em papel ou em slide), modelos de estudo e radiografias ou pela obtenção de imagens digitais com câmeras fotográficas digitais. Desta forma, o objetivo desse trabalho é esclarecer alguns conceitos básicos relacionados às imagens digitais e tentar responder às perguntas mais freqüentes em relação ao tema: Como digitalizar as minhas documentações ortodônticas com um scanner? Como obter imagens digitais com uma câmera fotográfica digital? Que tipo de resolução em DPI (dots per inch, ou pontos por polegada) ou em Megapixel (MP), tamanho e formato de arquivo devo utilizar para as minhas necessidades ortodônticas de rotina? A obtenção de imagens com finalidade apenas de visualização no monitor do computador é diferenciada daquela para outros fins, como impressão de relatórios, banners ou apresentações com recurso de multimídia? E por fim, qual resolução deve ser utilizada para obter imagens digitais que serão encaminhadas para publicações científicas?
\end{abstract}

Palavras-chave: Imagem. Imagem digital. Imagem em Ortodontia.

\section{INTRODUÇÃO}

Os avanços científicos e tecnológicos pelos quais a Ortodontia vem passando, desde a sua criação como especialidade odontológica, permitem aos profissionais desta área utilizar recursos, antes inimagináveis, facilitando a elaboração do diagnóstico e planejamento, bem como a avaliação crítica prospectiva e retrospectiva da evolução e resultado do tratamento ortodôntico.

Um dos grandes benefícios que a evolução tec-

* Mestrando em Ortodontia pelo COP - PUC/MG

** Professor do Curso de Mestrado em Ortodontia do COP - PUC/MG. 
nológica proporcionou à Ortodontia foi a utilização das imagens digitais. $\mathrm{O}$ uso desse novo recurso em Odontologia, e especificamente em Ortodontia, associado à introdução da Fotografia Digital, tem sido assunto de grande interesse nos últimos anos, sendo inegáveis as vantagens proporcionadas por essa nova tecnologia. Dentre essas, a possibilidade da visualização das imagens na tela do computador ou em projetores multimídia, a facilidade durante elaboração do diagnóstico e planejamento ortodôntico, o auxílio no gerenciamento das documentações ortodônticas na clínica, a assistência na comunicação entre profissionais, bem como com os pacientes, além da ilustração de comunicações científicas como conferências, cursos e publicações, sendo uma excelente ferramenta para o ensino e pesquisa.

Atualmente, é possível realizar algumas simulações do tratamento ortodôntico associado ou não à cirurgia ortognática, na tela do computador, com o objetivo de prever as mudanças faciais proporcionadas por esses. Uma nova evolução das imagens digitais são as imagens em três dimensões (3D), nas quais é possível avaliar os modelos ortodônticos e a face do paciente nos três planos do espaço.

Com o objetivo de lançar mão de todas as vantagens proporcionadas pela utilização das imagens digitais em Ortodontia é necessário transformar a documentação ortodôntica tradicional, composta basicamente por fotografias analógicas (em papel ou em slide), modelos de estudo e radiografias, em imagens digitais. Para isso, é necessário que toda a documentação seja digitalizada. Em contrapartida, com a utilização das fotografias digitais este processo não é necessário, pois essas já consistem de arquivos digitais.

Digitalizar uma imagem é transformá-la em um arquivo de computador, ou seja, o que é físico e palpável (por exemplo, um slide, modelo de estudo ou radiografia) passa a ser virtual (visualizado, por exemplo, na tela do computador).

Swartz ${ }^{30}$ ressaltou que embora a utilização de imagens digitais em Ortodontia proporcione diversas vantagens, muitos profissionais estão tendo grande dificuldade em digitalizar seus slides e apresentar seus casos clínicos por meio de recursos informatizados. Para este autor, os aspectos relacionados à resolução e tamanho das imagens, bem como sua obtenção, manipulação e armazenamento passaram a ter grande relevância para os ortodontistas que pretendem utilizar esta nova tecnologia.

Desta forma, o objetivo desse trabalho é esclarecer alguns conceitos básicos relacionados às imagens digitais e tentar responder às perguntas mais freqüentes em relação ao tema: Como digitalizar as minhas documentações ortodônticas com um scanner? Como obter imagens digitais com uma câmera fotográfica digital? Que tipo de resolução em DPI (dots per inch, ou pontos por polegada) ou em Megapixel (MP), tamanho e formato de arquivo devo utilizar para as minhas necessidades ortodônticas de rotina? A obtenção de imagens com finalidade apenas de visualização no monitor do computador é diferenciada daquela para outros fins, como impressão de relatórios, banners ou apresentações com recurso de multimídia? E por fim, qual resolução deve ser utilizada para obter imagens digitais que serão encaminhadas para publicações científicas? Por exemplo, a Revista Dental Press de Ortodontia e Ortopedia Facial, que exige em suas normas de publicação "imagens em alta resolução”, então qual será tal resolução?

\section{A IMAGEM DIGITAL}

A tecnologia da imagem digital propicia os meios de se codificar digitalmente documentos analógicos em forma de imagem digital para armazenagem, transmissão e recuperação em sistemas computadorizados ${ }^{33}$.

As imagens digitais podem ser produzidas por diversos aparelhos, incluindo câmeras de vídeo e fotográficas digitais, scanners, aparelhos de raios-X, microscópios eletrônicos, aparelhos de ultra-som e radares $^{6}$. Desta forma, deve-se diferenciar a ter- 
minologia "imagem digital" de "fotografia digital". Esta última é somente um tipo de imagem digital que é adquirida com o uso de câmeras fotográficas digitais.

Como os computadores utilizam um sistema de numeração binária, ou seja, apenas dois dígitos para representar qualquer caractere, seja este, um número, uma letra ou uma fotografia, as imagens digitais, bem como todos os arquivos digitais, nada mais são do que uma série de dígitos binários: 0 e $1 . \mathrm{Ou}$ seja, a imagem é uma longa seqüência destes dois números que, então, se "transformam" em quadros minúsculos. Cada pequeno quadro, denominado pixel (contração de picture X element, ou elementos da imagem), representa uma intensidade de luz e de cor que todos estes, em conjunto, irão formar a imagem digital ${ }^{12}$. Logo, a unidade básica formadora da imagem digital é o pixel.

Para facilitar o entendimento, observem a figura 1. O que nós vemos e interpretamos é uma fotografia intrabucal frontal de um paciente em tratamento ortodôntico. Na verdade, na linguagem binária dos computadores, essa fotografia nada mais é do que uma seqüência dos números 0 e 1 (Fig. 2).

De acordo com Swartz ${ }^{30}$, a menor unidade deste código binário é o bit (abreviatura de bynary digit, ou código binário), que pode ser 0 (zero)

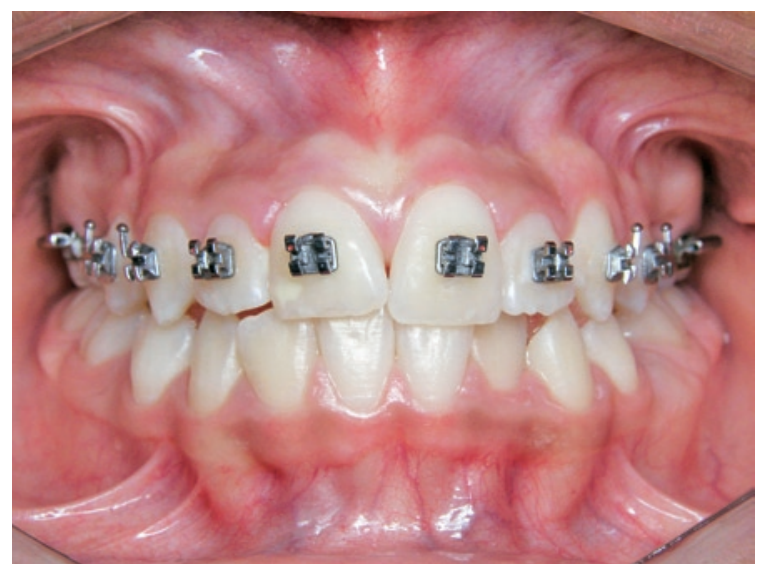

FIGURA 1 - Ilustração da nossa concepção de uma fotografia. ou 1 (um). Em seguida, à medida que mais informações são armazenadas, os arquivos passam a ser quantificados como bytes, que é a unidade de medida para mensurar o tamanho de arquivos digitais. Cada byte é composto por 8 bits. Um kilobyte (KB) equivale a 1.024 bytes. Um Megabyte (MB) representa $1.024 \mathrm{~KB}$ e um Gigabyte (GB) possui $1.024 \mathrm{MB}$.

\section{RESOLUÇÃO E DEFINIÇÃO}

A resolução das imagens digitais é a qualidade que esta apresenta, ou seja, quanto maior a resolução da imagem, maior definição de detalhes e conseqüentemente, melhor reprodução de cores, brilho e contraste. A resolução da imagem é diretamente proporcional à quantidade de pixel. $\mathrm{Ou}$ seja, quanto maior a quantidade de pixel (quantidade de pontos na imagem), maior será a qualidade da imagem ${ }^{10,14,15,27}$.

Mas é preciso ter em mente que, quanto maior a quantidade de pixel, e assim uma imagem com melhor resolução, maior será o tamanho do arquivo (em bytes) a ser salvo no computador, conseqüentemente ocupando mais "espaço" na memória ${ }^{10}$.

Outro conceito de fundamental importância é a definição da imagem. Ou seja, quanto maior a quantidade de pixel, maior será a resolução,

010110100001011000101000000100101 010010101000000101001001010001011 000101000010101000100100010100001 001010001100010000010100001010010 100001101000101010101100110001011 101000001010000010010001001010101 100100001010110000100110010111001 001011010010010010010100101010101 101001010000101000100101010101010 110001001010000001010111010010101 100010100001001010110001010010100 010001011000010110101010000101010 100010110101001110001100101010101 FIGURA 2 - Representação esquemática da figura 1 na linguagem dos computadores. 
mas não necessariamente a definição ${ }^{30}$. Esta estará diretamente relacionada com o tamanho que esta imagem será visualizada. Por exemplo, a figura 3 apresenta dimensão de 102 x 33 pixels com um tamanho de 4,3 x 1,4 cm. Nesse caso, como a resolução é baixa (60 DPI), é possível visualizar como a imagem é formada por pixels, fenômeno conhecido como pixelização, que retrata a falta de qualidade da imagem. Se o tamanho (em centímetros) da figura 3 for reduzido para $2,5 \times 0,8 \mathrm{~cm}$ (Fig. 4), por exemplo, a dimensão de 102 x 33 pixels permanece a mesma, porém a definição melhora. O oposto acontece se a figura 3 for aumentada de tamanho para $7,8 \times 2,5 \mathrm{~cm}$ (Fig. 5), por exemplo. A dimensão ainda continua a mesma, 102 x 33 pixels, porém a definição piorou. Esse fenômeno pode ser facilmente entendido ao se analisar o formato original retangular do pixel ${ }^{11}$. Quando uma imagem é visualizada na tela do computador, por exemplo, utilizando o programa Microsoft@ PowerPoint ${ }^{\circledR}$ (Redmond, WA, USA) para preparar uma apresentação, ao aumentá-la (esticá-la) ou diminuí-la (comprimi-la), a quantidade de pixels (dimensão) não é alterada, nem o tamanho original do arquivo (em bytes). Para alterar a dimensão ou o tamanho do arquivo, a imagem deve ser editada ou manipulada em programas (softwares) específicos como, por exemplo, o Adobe® Photoshop ${ }^{\circledR}$ (Seattle, WA, USA) e o Paint Shop ${ }^{\text {TM }}$ Pro® (Eden Prairie, MN, USA).

Desta forma, a única mudança que ocorre é na definição da imagem, ao aumentar uma imagem, o tamanho do pixel (que possui formato retangular) também é esticado o que facilita sua visualização, resultando na falta de definição da imagem. Quando a imagem é diminuída, o tamanho do pixel também diminui, o que dificulta a sua visualização, melhorando a definição. Concluindo, quanto maior a dimensão da imagem (quantidade de pixels), mais esta pode ser aumentada (estica$\mathrm{da}$ ), sem, contudo deixar os pixels aparentes, ou seja, perder definição ${ }^{30}$.

Por exemplo, a figura 6 possui dimensão de 1.023 x 336 pixels, com muito mais definição que a figura 3, porém o mesmo tamanho em $\mathrm{cm}$. Se esta imagem for aumentada (esticada) para um tamanho de 7,8 x 2,5 cm (Fig. 7), esta vai perder alguma definição, porém como a dimensão é muito maior que a figura 5, esta irá apresentar uma definição muito melhor, embora o tamanho seja o mesmo.

Ao se utilizar fotografias clínicas, os conceitos mencionados se aplicam da mesma forma. A figura 8 com tamanho de $6 \times 8 \mathrm{~cm}$, por exemplo, possui $1.600 \times 1.200$ pixels, com qualidade e definição satisfatória. Se uma parte dessa imagem for selecionada

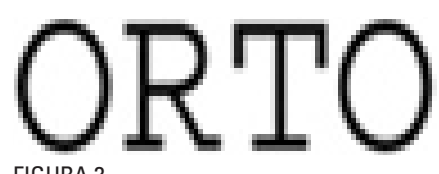

FIGURA 3

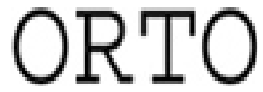

FIGURA 4

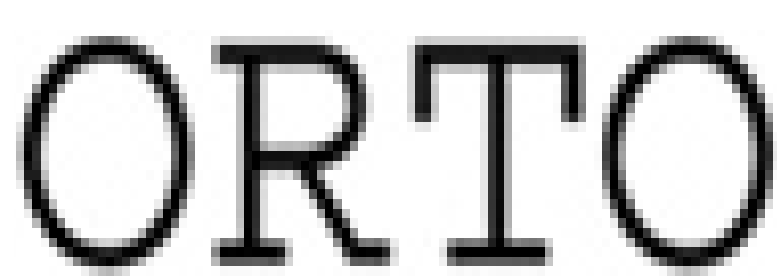

FIGURA 5

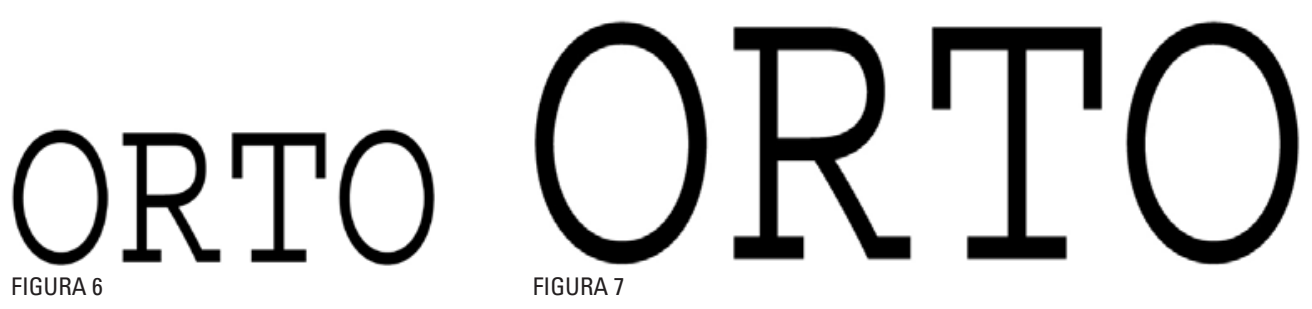



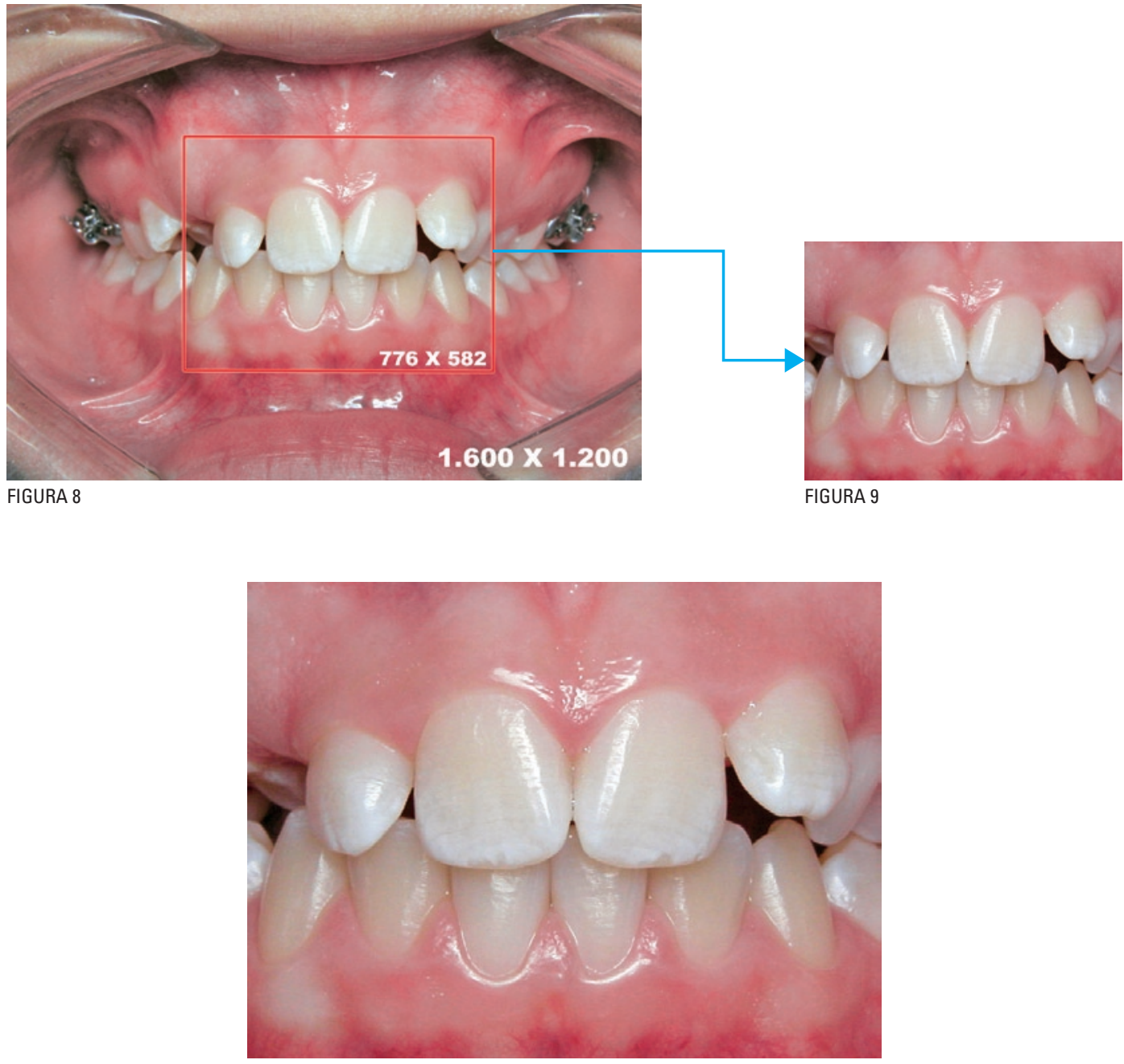

FIGURA 10

(3 x $4 \mathrm{~cm})$, por exemplo, e visualizada com a mesma proporção original (Fig. 9), a dimensão diminuiu para 776 x 582 pixels, porém a definição continua a mesma (os pixels nem foram esticados nem comprimidos). No entanto, se a figura 9 for aumentada (esticada) para o mesmo tamanho $(6 \times 8 \mathrm{~cm})$ que a figura 8, os pixels serão esticados e com isso a definição da imagem será diminuída (Fig. 10).

\section{DPI (DOTS PER INCH) E PPI (PIXELS PER INCH)}

Foi descrito anteriormente que a unidade de medida da resolução de uma imagem é o pixel e que quanto mais pixels tiver uma imagem, maior será sua resolução. A resolução também é comu- mente medida por meio de uma unidade chamada DPI (dots per inch, ou pontos por polegada). $\mathrm{Na}$ verdade, toda imagem, quando capturada digitalmente, é formada por PPI (ou pixels per inch, que quer dizer pixels por polegada). Quando impressa passa a ser definida por DPI, que deixa de ser virtual e passar a ser físico como qualquer impressão. Portanto, é correto dizer que tal imagem foi impressa em DPI, mas se estiver na tela de um computador, deve ser definida como PPI. Segundo Abelson ${ }^{2}$, embora estes dois termos sejam teoricamente diferentes, na prática são utilizados com o mesmo objetivo.

Então, o que significa DPI na prática? Ao se 
digitalizar uma fotografia com 300 DPI, por exemplo, está implícito que cada polegada linear da imagem, contém 300 pixels ou pontos e em cada polegada quadrada contém 90.000 (300 x 300), que em conjunto irão formar a imagem digital ${ }^{8,13}$.

Pode-se concluir, dessa forma, que quanto maior a quantidade de DPI, maior será a resolução da imagem e conseqüentemente, maior o tamanho (em bytes) do arquivo.

\section{PROFUNDIDADE DE BIT OU PROFUNDIDADE DE CORES}

Como mencionado anteriormente, o pixel é a unidade formadora da imagem digital e está relacionado com a resolução que esta possui. Porém, o pixel representa somente uma intensidade de cor. Ou seja, para cada pixel será determinado uma cor específica. Desta forma, para que uma imagem tenha alta qualidade além da quantidade suficiente de pixels, esta deve conter um amplo espectro de cores.

A terminologia "profundidade de cores" é atribuída à quantidade distinta de cores que uma determinada imagem apresenta. Muitas vezes, essa característica é chamada de "profundidade de bit", pois está diretamente relacionada ao número de bits utilizado por cada pixel para gerar as cores ${ }^{21}$. Quanto maior o número de bits atribuído a cada pixel, maior o número possível de tonalidades de cores disponíveis para cada pixel e conseqüentemente o tamanho do arquivo em bytes ${ }^{13}$.

De acordo com Busch ${ }^{8}$, uma imagem com uma profundidade de cor de 1 bit terá somente uma cor, que pode ser o branco ou o preto ( 0 ou 1 do código binário). Quanto maior a profundidade de cores (expressa em bits), maior será a quantidade de cores de uma imagem. Por exemplo, uma imagem com 4 bits de cores ( 4 bits por pixel) terá uma combinação de 24 cores, ou 16 possibilidades. Uma imagem com 8 bits possuirá uma combinação de $256\left(2^{8}\right)$ cores ou 256 tons de cinza, conhecidas como imagens em escala de cinza ${ }^{8,13}$.

A maioria das câmeras digitais e dos scanners possui a capacidade de gerar imagens com profundidade de cores de 24 bits, ou seja, 8 bits para cada canal de cor, resultando em 16.7 ( $\left.2^{24}\right)$ milhões de cores $^{31}$. Cada pixel formador desta imagem poderá utilizar uma entre as 16.7 milhões de combinações de cores disponíveis ${ }^{13}$. Estas imagens também são conhecidas como RGB, ou de três cores básicas, o vermelho, verde e azul (de onde vem a terminologia RGB do inglês, red, green and blue $)^{12,13}$. Isso significa que existem 256 tons de vermelho, 256 tons de verde e 256 de azul, resultando em uma imagem de 24 bits $(256 \times 256$ × $256=16.7$ milhões de cores $)^{31}$.

As imagens com o mínimo de 24 bits (16.7 milhões de cores) são conhecidas como true color (ou cores verdadeiras), pois apresentam características próximas à qualidade fotográfica ${ }^{20}$. Como o olho humano só pode distinguir algumas milhões de cores, a profundidade de cores de 24 bits em uma determinada imagem seria mais do que suficiente para representar a sua ampla diversidade de cores ${ }^{22}$.

Algumas câmeras fotográficas digitais e scanners mais sofisticados possuem a capacidade de operar com 12, 14 e 16 bits para cada canal RGB, resultando em uma profundidade de cores que pode chegar a 36, 42 e 48 bits, respectivamente, ou seja, trilhões de possibilidades de cores para cada pixel ${ }^{31}$. Como a capacidade do olho humano é bastante inferior a esse valor e a maioria dos programas utilizados pelos computadores, monitores e projetores de multimídia utilizam a profundidade de cores de 24 bits (RGB), atribuir às imagens esse valor é mais do que necessário para as diversas finalidades odontológicas. Então qual seria a razão dos fabricantes produzirem equipamentos com altíssimas profundidades de bit? Segundo Pctechguide $^{20}$, durante o processo de digitalização, algumas informações são perdidas, diminuindo dessa forma, a qualidade final da imagem. Por isso, a quantidade extra de dados seria utilizada para corrigir os eventuais erros durante a digitalização, além de otimizar pequenos detalhes da imagem, 
como por exemplo, regiões com transição muito suave entre diferentes tons (um dégradé, por exemplo) ${ }^{20,31}$. É importante ficar claro, que da mesma forma, quando se aumenta o número de pixels da imagem o arquivo digital torna-se maior, ao se aumentar a profundidade de cores da imagem, o mesmo efeito ocorre, o tamanho da imagem digital (em bytes) aumenta ${ }^{31}$.

Embora os monitores e projetores de multimídia utilizem o padrão RGB de cores, as impressoras utilizam o padrão CMYK. Essas imagens são formadas pela combinação de quatro cores básicas, ciano, magenta, amarelo e preto ${ }^{11,13}$. O fato das telas de computadores e projetores de multimídia utilizarem um padrão de cor (RGB) diferente das impressoras (CMYK) compromete a fidelidade entre a imagem vista no monitor e na fotografia impressa ${ }^{11}$. Isto explica porque, muitas vezes, ao se digitalizar fotografias analógicas, estas alteram a qualidade quando são visualizadas nos monitores. $\mathrm{O}$ mesmo ocorre quando imagens digitais são impressas.

\section{FORMATOS DE ARQUIVOS}

O formato de arquivo é a forma como a imagem será armazenada, isto é, guardada ou "salva" no scanner, ou na câmera fotográfica digital, e posteriormente transferida para o computador. Existem inúmeros formatos, porém os mais utilizados

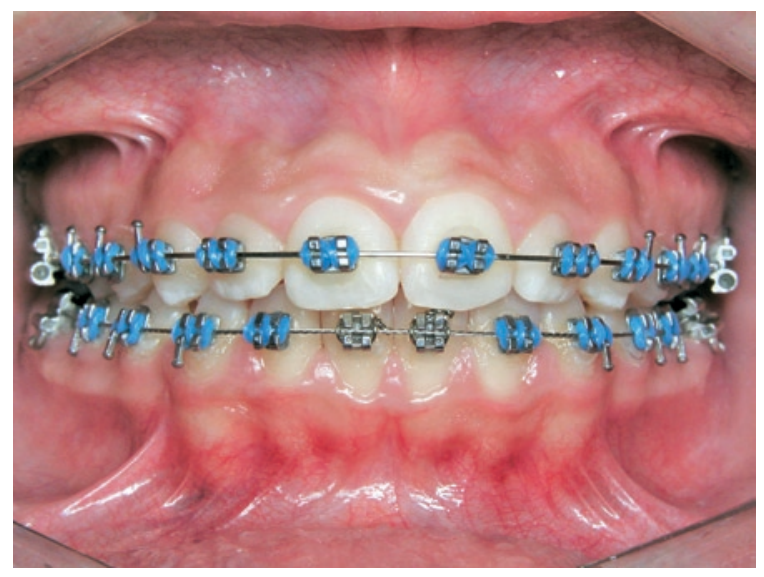

FIGURA 11 - Exemplo de imagem no formato JPEG. para a obtenção de imagens digitais são o JPEG (ou .jpg) e o TIFF (ou .tif) ${ }^{2,7}$.

O formato JPEG (Joint Photographic Experts Group) é o mais popular, pois é rápido e fácil de trabalhar nos diversos programas de edição de imagens, além de ocupar pouco espaço (em bytes) no disco rígido do computador. A grande desvantagem desse formato é que a qualidade final da imagem é diminuída através de sua compressão, ou seja, alguns pixels são descartados (eliminados). No formato TIFF (Tagged Image File Format), por sua vez, não existe nenhuma compressão da imagem, logo, esta é armazenada com a mínima perda de qualidade. A desvantagem é que como nenhuma informação (pixels) é eliminada, este tipo de formato ocupa muito espaço (em bytes) no disco rígido do computador ${ }^{2,7,12}$.

O formato de escolha vai estar diretamente relacionado com a finalidade da fotografia. Devido à sua facilidade de uso e à melhor relação qualidade/tamanho de arquivo, o formato JPEG é mais comumente utilizado, e este deve ser o de escolha em Odontologia. Segundo Askey ${ }^{5}$, a ampla utilização desse tipo de formato está relacionada com a sua capacidade de reduzir o tamanho do arquivo de uma fotografia, de 8 a 10 vezes, sem nenhum tipo de perda da qualidade final da imagem que possa ser detectada pelo olho humano a uma distância normal. Por exemplo, a figura 11, com 3 MP,

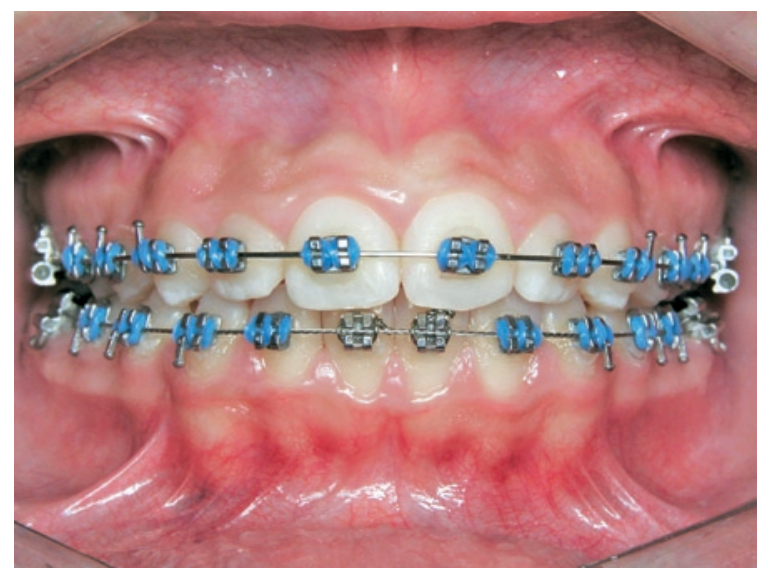

FIGURA 12 - Imagem idêntica à FIG. 11, porém no formato TIFF. 
que no formato JPEG ocupa $1,7 \mathrm{MB}$ será dificilmente diferenciada da mesma fotografia (Fig. 12) no formato TIFF que ocupa $9 \mathrm{MB}$. Em alguns poucos casos, como a utilização de imagens com finalidade de pesquisa científica, ou quando o fator qualidade é primordial, pode-se optar pelo formato TIFF.

Mais uma excelente vantagem da imagem digital, quando armazenada nesses formatos (JPEG e TIFF), é a possibilidade de ser editada e manipulada (em programas específicos para edição de imagens) com o objetivo de melhorar a qualidade, remover defeitos e objetos indesejados e padronizá-las ${ }^{27,30}$.

Diferente dos arquivos JPEG e TIFF existe um outro formato, o RAW, que não pode ser editado, manipulado ou modificado, e assim garante a "veracidade" das imagens digitais gravadas nesse formato $^{6,31}$. Além dessa grande vantagem, esse tipo de arquivo, assim como o TIFF, não causa nenhum tipo de compressão na imagem, preservando a sua qualidade e ocupando menos espaço na "memória" do que o formato TIFF ${ }^{6}$. É claro, que com o objetivo de realizar qualquer tipo de alteração em uma imagem com esse formato, podese "salvar" esse arquivo em um outro formato, como o JPEG ou TIFF, e então, realizar qualquer manipulação necessária ${ }^{31}$. Vale ressaltar que a alteração foi realizada em um arquivo "novo" enquanto que o original (RAW) manteve-se preservado. O fato do formato RAW ser um sistema de arquivamento que não permite nenhum tipo de manipulação, isto é, a imagem, quando nesse formato, não pode ser modificada por ninguém, proporciona à fotografia uma propriedade testemunhal o que parece ser uma excelente opção para

\begin{tabular}{|c|c|}
\hline $\begin{array}{c}\text { Tabela } 1 \text { - Principais dispositivos para obtenção e utiliza- } \\
\text { ção de imagens digitais. }\end{array}$ \\
\hline Dispositivo & Finalidade \\
\hline Scanner & Entrada \\
\hline Câmera fotográfica digital & Entrada \\
\hline Monitor & Saída \\
\hline Projetor multimídia & Saída \\
\hline Impressora & Saída \\
\hline
\end{tabular}

garantir o valor legal das imagens digitais.

O formato RAW é desenvolvido especificamente para alguns fabricantes como a Nikon, Canon, Kodak, Sinar, dentre outros, o que é uma grande desvantagem, pois, como cada empresa desenvolve o seu, não existe um tipo de formato RAW padrão $0^{6,31}$. Outro problema desse tipo de arquivo é que não é possível editá-los em qualquer programa de edição de imagens, pois, é necessário um adaptador específico para que o programa possa processar esses arquivos ${ }^{6}$.

\section{INPUT (ENTRADA) E OUTPUT (SAÍDA)}

O entendimento desses dois conceitos é de fundamental importância para a obtenção de imagens digitais com uma relação qualidade/tamanho de arquivo satisfatória.

Antes de entrar nesse assunto propriamente dito, é necessário relembrar alguns conceitos de informática.

Para que um computador execute sua função, este é auxiliado por diversos dispositivos (chamados de periféricos) que podem ser de entrada (input) ou de saída (output). Os periféricos de entrada, como por exemplo, o teclado, o mouse e o scanner, coletam informações do mundo exterior e os enviam para o computador. Este por sua vez pode armazenar a informação ou enviá-la (transmiti-la) para o meio externo através dos periféricos de saída, como por exemplo, o monitor e a impressora.

Esses conceitos podem ser plenamente aplicados e irão facilitar a obtenção e a utilização das imagens digitais de forma bastante simplificada. $\mathrm{O}$ local primário de obtenção das imagens digitais é chamado de entrada ou input e pode ser o scanner ou a câmera fotográfica digital. O local onde a imagem será visualizada é chamado de saída ou output e pode ser a tela do computador, um projetor de multimídia ou uma impressora. A tabela 1 resume os principais periféricos utilizados para a obtenção (entrada) e visualização (saída) de imagens digitais que serão o foco principal desse trabalho. 


\section{OBTENÇÃO DE IMAGENS DIGITAIS POR MEIO DE SCANNERS}

Os scanners são dispositivos (de entrada) utilizados para converter imagens em arquivos digitais. Dentre as diversas finalidades dos scanners, o processo de digitalização de imagens (em papel ou em slide) tem grande relevância para a nossa área.

Existem, no mercado, três tipos básicos de scanners, os de mão (que provavelmente, não são mais comercializados) os de mesa e os de slide ${ }^{24}$. Os de mesa permitem digitalizar imagens de folhas de papel e de objetos mais espessos como livros e revistas. Esse tipo também pode ser utilizado para digitalizar slides, negativos e radiografias através da adaptação de leitores de transparência e alguns fabricantes já incluem no scanner esse acessório ${ }^{24}$. Os scanners de slides, também chamados de "dedicados", são específicos para a digitalização e processamento de slides.

E agora? Como obter imagens digitais por meio de um scanner seja este de mesa ou específico para slide? Dentre as diversas variáveis que podem influenciar no processo de digitalização as principais são: a resolução, o tamanho e o tipo de arquivo.

A resolução e definição, como descrito anteriormente, estão relacionadas à qualidade da imagem, e esse é o nosso objetivo, obter imagens com excelente qualidade. Porém, a idéia de que quanto maior a resolução, melhor será a qualidade, deve ser muito bem avaliada. $\mathrm{O}$ motivo é porque a resolução na qual uma imagem será digitalizada está intimamente relacionada com o tamanho do documento original e com a finalidade da imagem. Em outras palavras, qual será a saída (output) da imagem? Será visualizada na tela do computador, em um projetor multimídia ou impressa por meio de uma impressora? Cada um desses dispositivos possui uma determinada característica que deve ser avaliada antes da digitalização de imagens com essas finalidades.

Desta forma, o ideal é obter imagens de forma simples e rápida com qualidade satisfatória e tamanho em bytes mínimo para não ocupar muito espaço na memória do computador e não dificultar a performance das apresentações no Microsoft ${ }^{\circledR}$ PowerPoint ${ }^{\circledR}$ (Redmond, WA, USA). Não é surpresa se alguém relatar que teve problemas durante a utilização desse programa (software) por trabalhar com arquivos (aulas) muito "carregados". Além disso, as imagens digitais devem possuir resolução suficiente para a obtenção de qualidade na impressão de painéis (posters ou banners) e em publicações científicas.

Segundo Ritto ${ }^{25}$, a resolução da tela dos computadores pode variar de baixa (640 x 680 pixels), média (800 x 600 pixels) e alta (1.024 x 768 pixels). As imagens visualizadas nos monitores apresentariam, em média, a resolução variando de 72 a $96 \mathrm{PPI}^{2,19,25,30}$. Mais recentemente foi lançado no mercado alguns monitores que podem chegar à resolução de 2.048 x 1.536 pixels. Porém, apesar da qualidade gerada por esses novos monitores ser surpreendente, o custo desta tecnologia ainda encontra-se bastante elevado.

Em relação aos diversos projetores multimídia disponíveis no mercado, a resolução da grande maioria é de 800 x 600 pixels ou de 1.024 x 768 pixels, semelhante às telas dos computadores (72 a 96 PPI). Uma nova geração de projetores multimídia com altíssima resolução podendo chegar até 1.600 x 1.200 pixels, também foi lançada no mercado, porém com o custo ainda elevado.

Desta forma, sugere-se que durante a utilização de um scanner para a digitalização de imagens (em papel ou em slide) com a finalidade de serem exibidas na tela do computador ou em projetores de multimídia utilize-se a resolução (entrada) de 150 DPI. A razão principal é que de nada adianta digitalizar uma imagem com resoluções altíssimas, como por exemplo, 1.200 DPI (com 1.200 pontos em cada polegada linear da imagem) e projetar em uma tela de computador, pois a resolução máxima que um excelente monitor ou um projetor de multimídia comporta é de 90 PPI, em média.

Para a simplificação desse conceito pode-se utilizar a seguinte analogia. Imaginem-se dentro 
de um automóvel em um trânsito totalmente congestionado. A velocidade máxima viável nesse momento é de $20 \mathrm{Km} / \mathrm{h}$, mas você está em um veículo que pode atingir a velocidade máxima de $270 \mathrm{Km} / \mathrm{h}$ (uma Ferrari, por exemplo). Qual a vantagem de poder atingir tal velocidade nesse momento? Nenhuma, excluindo o fato de você estar dentro de uma Ferrari, é claro! Infelizmente, embora o automóvel alcance tal velocidade, não será possível utilizar este recurso. Com a resolução das imagens acontece o mesmo. Uma imagem digitalizada com 1.200 DPI possui excelente qualidade, porém, da mesma forma que o automóvel não pode ultrapassar os $20 \mathrm{Km} / \mathrm{h}$, a imagem não terá os seus mil e duzentos pontos por polegada linear visíveis, mas sim a capacidade máxima da tela do computador ou do projetor de multimídia. Por outro lado, da mesma forma que o automóvel pode ser utilizado com uma velocidade maior em uma pista de corrida, pode-se utilizar altas resoluções em outras situações.

Então por que a resolução de 300 DPI é a mais conhecida e é sinônimo de qualidade? A resposta para essa pergunta é porque esse é o padrão para proporcionar impressões com qualidade fotográfica $^{2,4,12,19,25}$. De acordo com Abelson ${ }^{4}$, o termo "qualidade fotográfica" pode ser definido como uma imagem com qualidade equivalente àquelas produzidas e processadas por filmes fotográficos convencionais.

Ao entrar mais profundamente no assunto, o seguinte questionamento é feito: por que a resolução de 300 DPI apresenta qualidade fotográfica? A resposta está diretamente relacionada à capacidade do olho humano. Segundo Alt e Noda ${ }^{1}$ a capacidade do olho humano é de enxergar aproximadamente 10 linhas por milímetro a uma distância normal. Em outras palavras, a acuidade visual normal possibilita ao olho humano a capacidade de distinguir objetos separados em um intervalo de $0.1 \mathrm{~mm}$ a uma distância de $25 \mathrm{~cm}^{32}$. A resolução de 300 DPI possui 300 pontos em uma polegada linear ou 300 pontos a cada 25,4 mm. Aplicando uma regra de três (300/25.4), essa resolução apresentaria 11,8 pontos para cada milímetro linear, o que seria, mais ou menos, 1 ponto a cada $0,1 \mathrm{~mm}$. Desta forma, a resolução de 300 DPI apresenta aproximadamente 1 ponto a cada $0.1 \mathrm{~mm}$, o suficiente para permitir a visualização de uma imagem em tom contínuo.

Embora a literatura descreva a capacidade máxima do olho humano para distinguir pontos próximos e diferentes cores, deve-se ter muito cuidado ao se realizar esse tipo de afirmação. $\mathrm{O}$ olho humano não é digital e os seres humanos não são feitos de forma padronizada (como a fabricação de um scanner, por exemplo), dessa forma, as variações individuais irão resultar em diferentes capacidades visuais. A finalidade desses parâmetros matemáticos é estabelecer padrões para simplificar a utilização das imagens digitais nas suas diversas finalidades.

Desta forma, sugere-se a resolução de 300 DPI (entrada) durante a utilização de um scanner para a digitalização de imagens (em papel ou em slide) com a finalidade de serem impressas em impressoras jatos de tinta, utilizadas para elaboração de painéis (embora alguns equipamentos utilizados para "plotar" os painéis não comportem tal resolução) ou para a publicação de artigos científicos. Mais uma vez, de nada adianta digitalizar uma imagem com 1.800 DPI, por exemplo, pois a resolução média que grande parte das revistas científicas utilizam é de 300 DPI. Em outras palavras, as impressoras utilizadas pelas editoras têm a capacidade de colocar (imprimir) 300 pontos (ou pixels) em cada polegada linear da imagem ${ }^{31}$.

Em relação às impressoras jatos de tinta comumente utilizadas nos consultórios odontológicos, atualmente, estas possuem a resolução máxima média que varia de 600 a 1.440 DPI. Algumas dessas, chamadas impressoras fotográficas possibilitam resoluções ainda maiores. Dessa forma, como poderíamos explicar essas altíssimas resoluções se o padrão é 300 DPI? A resposta esta diretamente relacionada com a quantidade de cartuchos 
(de cores ou de pigmentos) que elas utilizam, ou seja, a resolução total deve ser dividida pela quantidade de cartuchos e com isso, o resultado final (ou resolução real) estaria dentro dos 300 DPI. Por exemplo, algumas impressoras fotográficas da marca Epson (Epson do Brasil, Barueri, SP) que trabalham com seis cartuchos e possuem a resolução de 1.440 DPI, possuem a resolução real de 240 DPI (1.440/6). A resolução verdadeira média das impressoras jato de tinta atualmente varia de 240 a 360 DPI. Vale ressaltar que tal característica só é alcançada quando são seguidas todas as diretrizes propostas pelos fabricantes como a utilização de papéis específicos e cartuchos de tinta originais e novos, o que na maioria das vezes torna-se um processo pouco viável.

A resolução de 300 DPI também pode ser utilizada para a digitalização de fotografias que serão posteriormente encaminhadas para a "revelação digital" em laboratórios especializados. Os equipamentos mais utilizados pelos laboratórios no país são os modelos da linha Frontier da Fuji (FujiFilm do Brasil, Manaus, AM) e os modelos da Noritsu (Noritsu do Brasil S/A, Manaus, AM), que comportam a resolução máxima de 300 e 400 DPI, respectivamente.

Conclui-se que para todas essas finalidades acima descritas a resolução de 300 DPI seria mais do que suficiente. Por outro lado, caso uma imagem seja digitalizada com 100 DPI (entrada) e impressa em um equipamento com capacidade de impressão de 300 DPI (saída), esta provavelmente não apresentará qualidade satisfatória, pois será possivel identificar os pixels na imagem impressa. Para confirmar esse exemplo, o leitor pode fazer o seguinte teste: capturar (salvar) uma imagem disponível na Internet e imprimir em uma impressora jato de tinta. Como a resolução utilizada por imagens na Internet é de baixa qualidade, em torno de 72 DPI enquanto a impressora comporta muito mais, a imagem impressa não apresentará qualidade satisfatória, talvez seja possível observar o efeito pontilhado na imagem (pixelização).
Resumindo, a regra de ouro sugerida por Swartz ${ }^{30}$ durante o processo de digitalização de imagens é: a resolução utilizada de entrada (input) deve estar compatível com a finalidade da utilização da imagem ou saída (output).

Porém, o que acontece na maioria das vezes é que ao se digitalizar uma imagem com um scanner, seguindo as configurações originais do equipamento, a imagem com a resolução selecionada é muito pequena e precisa ser aumentada (esticada) para ser utilizada com a finalidade desejada. Desta forma, perdendo em definição como foi explicado anteriormente.

Isto ocorre porque o número total de pixels criados a partir de uma imagem digitalizada é determinado tanto pela resolução do scanner quanto pelo tamanho físico original do documento ${ }^{13}$. A configuração original da maioria dos scanners digitaliza as imagens em uma proporção (ou escala) de 1:1 ou de 100\%. Em outras palavras, ao se digitalizar um slide de $35 \mathrm{~mm}(2,4 \times 3,6 \mathrm{~cm})$ com 150 DPI, por exemplo, a imagem obtida terá a resolução de 150 DPI em um tamanho original de $2,4 \times 3,6 \mathrm{~cm}$. Como esse tamanho, na maioria das vezes não é suficiente, é necessário aumentar (esticar) a imagem, desta forma, mantém-se a resolução de $150 \mathrm{DPI}$, porém, quanto mais se estica a imagem para a finalidade desejada, esta perde definição. Portanto, a relação entre a resolução de digitalização e a resolução de saída se baseia no tamanho do original ${ }^{13}$.

Para minimizar tal inconveniente as imagens devem ser digitalizadas por meio de dois recursos diferentes que produzem resultados semelhantes: alterar a escala de proporção ou alterar a resolução de entrada. A primeira opção é utilizar uma escala de proporção de acordo com o tamanho de saída desejado. Em outras palavras, ao ajustar a escala de proporção do scanner para 1:2 (200\%), $1: 3(300 \%)$ ou $1: 4$ (400\%), a imagem formada (saída) será duas, três ou quatro vezes maior que a original (entrada), respectivamente. Efeito semelhante ocorre se a resolução de entrada for duplicada, 
triplicada ou quadruplicada, respectivamente.

Esse fato pode ser explicado ao se realizar o cálculo da quantidade efetiva de pixels em ambas as opções ${ }^{13}$. Por exemplo, ao se digitalizar uma imagem com tamanho original de 4" x 5" (10,1 $\mathrm{x} 12,7 \mathrm{~cm})$ a 100 DPI e uma escala de $1: 1$ ou 100\%, resultará em 200 mil pixels (400 pixels na horizontal x 500 pixels na vertical). Se o objetivo for imprimir a imagem com o dobro do tamanho, pode-se aumentar a escala para 1:2 ou 200\%, o que resultará em uma imagem com 8" x 10 " com 800 mil pixels (800 pixels na horizontal x 1.000 pixels na vertical). Se esta imagem for digitalizada com o dobro da resolução (200 DPI) e a escala não for alterada $(1: 1)$, a imagem final terá o mesmo tamanho (4" x 5", ou 10,1 x 12,7 cm) resultando na mesma quantidade efetiva de $800 \mathrm{mil}$ pixels (800 pixels na horizontal x 1.000 pixels na vertical). Para reproduzir um original de slide 35 $\mathrm{mm}(2,4 \times 3,6 \mathrm{~cm})$ com um tamanho de saída de $14,4 \times 21,6 \mathrm{~cm}$ (seis vezes o tamanho do original) e resolução de saída de 300 DPI, a imagem precisa ser digitalizada com uma resolução de entrada de 1.800 DPI (seis vezes o tamanho do original) ou utilizar a resolução de 300 DPI de entrada e uma escala de 1:6 ou $600 \%$.

A figura 13, por exemplo, mostra a área disponível do programa Microsoft ${ }^{\circledR}$ PowerPoint ${ }^{\circledR}$

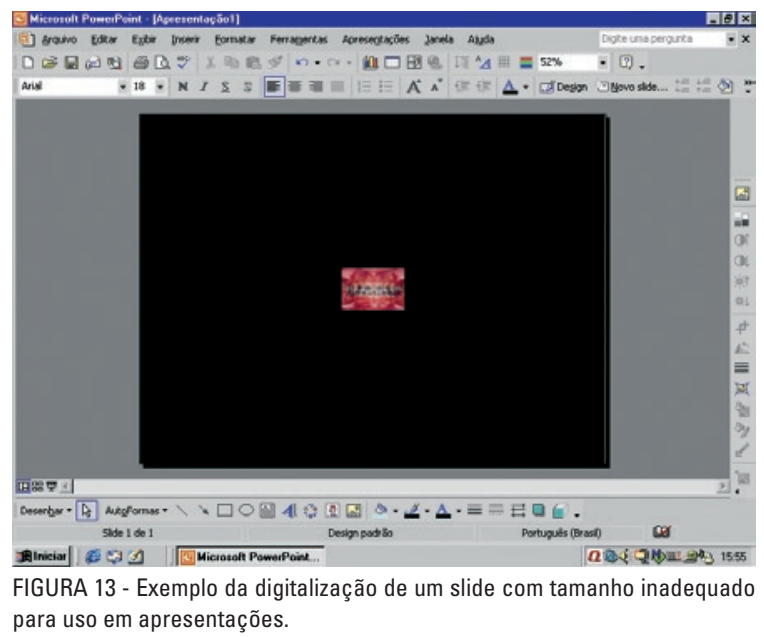

(Redmond, WA, USA) para a preparação de apresentações. No centro da tela pode-se observar uma imagem de um slide $35 \mathrm{~mm}$ que foi digitalizada por meio de um scanner com resolução de 150 DPI e uma escala de $1: 1$ ou de $100 \%$ a depender do modelo do scanner. Embora a resolução esteja correta para a finalidade desejada, a imagem está muito pequena (pois a original era um slide de $35 \mathrm{~mm}$ ), desta forma, ao se esticar a imagem para o tamanho desejado, sua definição vai diminuir (pois os pixels serão esticados), piorando a qualidade final.

Em contrapartida, pode-se observar na Figura 14, que o mesmo processo de digitalização, utilizado para a ilustração da figura 13, de um slide $35 \mathrm{~mm}$ que se encontra no centro da tela foi realizado. Embora ambas as imagens tenham sido digitalizadas com a mesma resolução (150 DPI), a imagem na figura 14 é quatro vezes maior que a imagem na figura 13, pois esta foi digitalizada com uma proporção de 4:1 (ou 400\%). Com isso, não será necessário aumentar a imagem, pois esta já se encontra com um tamanho adequado. $\mathrm{O}$ mesmo efeito seria alcançado se a imagem fosse digitalizada com uma escala de 1:1 (100\%) e resolução de 600 DPI. Alguns modelos de scanners da marca Genius (Yung Kang, Tainan, Taiwan), como por exemplo, o ColorPage - HR6X, somente dispo-

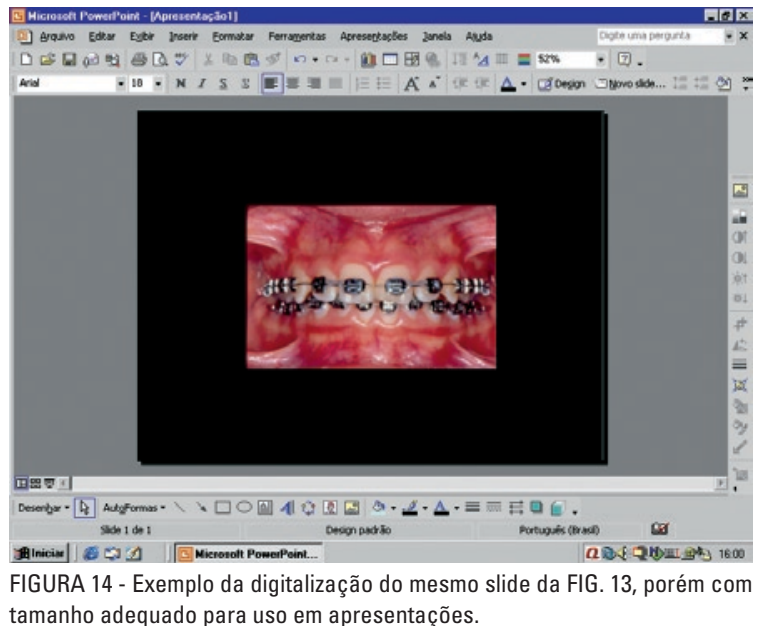


nibilizam a digitalização de slides com resolução mínima de 600 DPI.

Pode-se concluir que com a finalidade de digitalizar slides $35 \mathrm{~mm}$ que serão visualizados em monitores e em projetores de multimídia, pode-se trabalhar com a resolução de 150 DPI e uma proporção de $400 \%$ ou utilizar a resolução de 600 DPI sem alterar a escala (1:1 ou 100\%). Desta forma, obtém-se a resolução compatível com o equipamento de saída utilizado, associado a uma definição satisfatória.

Para a digitalização de imagens com a finalidade de publicações científicas ou para a elaboração de painéis, a resolução de 300 DPI deve estar associada a uma escala de proporção condizente com o tamanho final necessário para a impressão. Como, na maioria das vezes, não se sabe qual é o tamanho final que a imagem será utilizada para a edição final dos trabalhos, sugere-se que durante a digitalização de slides $35 \mathrm{~mm}$, a escala seja, em média de $400 \%$. Isto proporcionaria uma imagem final com qualidade fotográfica (300 DPI) quatro vezes maior que o tamanho do slide, ou seja, um tamanho de 9,6 x 14,4 cm. Efeito semelhante pode ser alcançado se a escala for mantida constante $(1: 1$ ou $100 \%)$ e a resolução de entrada for quatro vezes maior (1.200 DPI). Como o tamanho de imagem utilizado pela maioria das nossas necessidades ortodônticas de rotina, geralmente, não ultrapassa o tamanho de $10 \times 15 \mathrm{~cm}$, como por exemplo, impressão de relatórios, confecção de banners, revelação em laboratórios especializados e utilização em publicações científicas, esta sugestão seria suficiente para todas essas finalidades. Porém, caso o tamanho final seja maior do que 9,6 x $14,4 \mathrm{~cm}$, pode-se aumentar a escala para atingir o tamanho final necessário.

Após o entendimento desses conceitos, pode-se concluir que na maioria dos casos, para as diversas finalidades odontológicas, serão utilizadas resoluções entre 150 e 300 DPI. Dessa forma, o seguinte questionamento é feito? Por que a resolução dos scanners de mesa e os específicos para slide pos- suem capacidades altíssimas, que variam de 300 a $2.400 \mathrm{DPI}$, podendo chegar até $4.800 \mathrm{DPI}$ de resolução real? A resposta está diretamente relacionada com o tamanho do material utilizado para a digitalização e o tamanho final da imagem, pois quanto menor for o original, mais alta deve ser a resolução de digitalização ${ }^{13}$. Por exemplo, se o objetivo é digitalizar um slide de $35 \mathrm{~mm}$ com a finalidade de ampliar a imagem para ser utilizada em um outdoor, resoluções e escalas altíssimas devem ser utilizadas. Pode-se concluir que quanto mais alta a resolução de um scanner, mais este poderá ampliar uma imagem do seu tamanho original para o tamanho de saída ${ }^{13}$.

Outro conceito de fundamental importância é a diferença entre resolução real e resolução interpolada. A primeira também chamada de resolução óptica é baseada na capacidade do scanner em transformar luz em carga elétrica, gerando assim, os pixels ${ }^{13}$. Nesse tipo de resolução, que varia em média de 300 a 2.400 DPI entre os diversos scanners no mercado, a imagem pode ser digitalizada com máxima resolução sem alterar a sua qualidade final2,13,17. Na resolução interpolada (ou artificial), recurso utilizado por scanners, câmeras digitais e programas de edição de imagem, a imagem é ampliada por um processo conhecido como interpolação e o espaço criado é preenchido por novos pixels, resultando em uma resolução final que pode chegar até 24.000 DPI. Porém este tipo de recurso que envolve a criação de novos pixels por meio de equações matemáticas diminui sensivelmente a qualidade final da imagem, não reproduzindo de forma fiel pequenos detalhes e informações $2,8,13,17,19$. Dessa forma, durante a digitalização de imagens, deve-se optar pela resolução óptica do scanner, pois esta não altera a qualidade final da imagem.

Com o objetivo de simplificar o processo de digitalização de slides $35 \mathrm{~mm}$ para suas diversas finalidades em Odontologia, a tabela 2 resume as duas opções sugeridas para resolução e tamanho necessário para as principais situações utilizadas. 
Para se estabelecer a resolução ideal quando o tamanho original da imagem é mantida (escala de 1:1) é necessário algumas contas matemáticas e além disso, o limite do tamanho máximo de impressão é mantido constante. Em contrapartida, é mais simples escolher a resolução em DPI do periférico de saída e alterar o tamanho final da imagem desejada, aumentando ou diminuindo a escala de proporção.

Detalhe de grande importância que deve ser avaliado quando da obtenção de imagens digitais é a calibração dos monitores ${ }^{31}$. Estes variam muito em qualidade, tempo de uso, condições de iluminação e cores presentes no ambiente, podendo em alguns casos, mascarar a condição real da qualidade das imagens digitais.
Desta forma, passo de fundamental importância para simplificar a obtenção e a utilização de imagens digitais com qualidade é o ajuste e a calibração das cores utilizadas pelos monitores. Trigo $^{31}$ sugere que para se observar imagens digitais o ajuste da profundidade de cores é o mais importante e deve-se utilizar sempre a opção "milhões de cores". Para realizar tal ajuste, deve-se selecionar na área de trabalho (tela principal do computador), clicando com o botão direito do mouse, a opção "Propriedades". Uma janela será aberta com diversas opções para o gerenciamento das propriedades da tela do computador. Seleciona-se a opção "Configurações" e em seguida no ícone "Cores" a opção de no mínimo 24 bits (pois como foi descrito anteriormente este é valor mínimo necessário

\begin{tabular}{|c|c|c|c|}
\hline \multicolumn{4}{|c|}{ Tabela 2 - Sugestão de resolução para a digitalização de imagens com a utilização de scanners. } \\
\hline Finalidade & Resolução & Escala & Formato de arquivo \\
\hline Monitor & $150 \mathrm{DPI}$ & $1: 4$ ou $400 \%$ & JPEG \\
\hline $\begin{array}{c}\text { Projetor multimídia } \\
\text { Impressora }\end{array}$ & $150 \mathrm{DPI}$ & $1: 4$ ou $400 \%$ & JPEG \\
\hline & $300 \mathrm{DPI}$ & $1: 4$ ou $400 \%$ & JPEG \\
\hline Monitor & OU & $1: 1$ ou $100 \%$ & JPEG \\
\hline Projetor multimídia & $600 \mathrm{DPI}$ & $1: 1$ ou $100 \%$ & JPEG \\
\hline Impressora & $600 \mathrm{DPI}$ & $1: 1$ ou $100 \%$ & JPEG \\
\hline
\end{tabular}

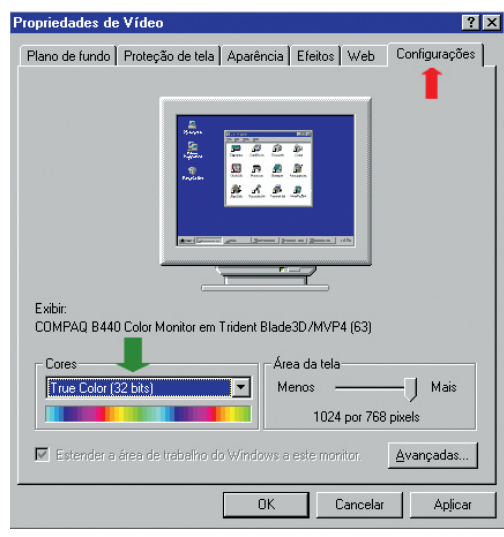

FIGURA 15 - Imagem da tela do computador quando 0 ajuste da profundidade de cores é modificado. A seta vermelha indica a pasta "Configurações" que deve ser acessada e a seta verde mostra o local no qual 0 ajuste é realizado.

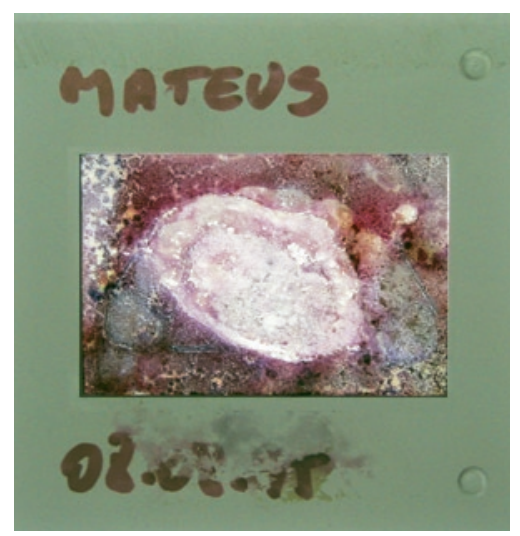

FIGURA 16 - Exemplo de fotografia de baixa qualidade que inviabiliza sua digitalização.
FIGURA 17 - Exemplo de slide em péssima condição para o processo de digitalização. 
para se trabalhar com cores verdadeiras), que neste exemplo é a opção True Color com profundidade de 32 bits (Fig. 15). Além do ajuste dos monitores, outras variáveis podem influenciar a qualidade das imagens visualizadas nos monitores como a placa de vídeo utilizada pelo computador e o seu driver (programa ou software) de instalação.

É importante explicitar que a qualidade da imagem digitalizada estará diretamente relacionada ao equipamento utilizado e a condição inicial do material fonte (entrada). Segundo Lopes et al. ${ }^{17}$, na maioria das vezes, o processo de digitalização de imagens por meio de scanners diminui sensivelmente a qualidade inicial da fotografia analógica devido à limitação dos equipamentos utilizados para esse processo. Em relação à situação original do material fonte, se este for de baixa qualidade, o arquivo digital resultante não apresentará resultados favoráveis, mesmo se uma resolução elevada for utilizada $^{16,24}$. Por exemplo, a digitalização de uma fotografia completamente fora de foco (Fig. 16) ou de um slide parcialmente destruído por mofo (Fig. 17) será comprometida, mesmo se altas resoluções e equipamentos de extrema qualidade forem utilizados.

\section{OBTENÇÃO DE IMAGENS DIGITAIS POR MEIO DE CÂMERAS FOTOGRÁFICAS DIGITAIS}

Atualmente, é impossivel falar de fotografia sem se enveredar pela captura digital de imagens. Este novo sistema denominado "Fotografia Digital" é apenas a evolução do método convencional de obtenção de fotografias. Enquanto que na fotografia analógica as imagens são formadas nos filmes fotográficos à base de cristais de prata, o sistema digital conta com um dispositivo eletrônico que transforma luz em impulsos elétricos e que posteriormente irão formar a imagem digital. A segunda grande evolução é que as fotografias digitais não são necessariamente "reveladas" por nenhum tipo de processo químico para obter as imagens, e sim, são armazenadas como arquivos digitais em computadores.
A utilização da fotografia digital em Odontologia, e especificamente em Ortodontia, tem despertado grande interesse dos profissionais, nos últimos anos, devido às diversas vantagens proporcionadas pelo mesmo. Dentre essas, a possibilidade da visualização imediata do resultado das fotografias, a eliminação do custo com filmes e revelação, além da sistematização do gerenciamento das imagens na clínica são as principais vantagens do sistema digital, tornando esse método de obtenção de imagens tentador.

A evolução tecnológica destes equipamentos possibilitou a existência de uma gama de variedades de câmeras digitais com características distintas. Dentre as diversas características desses equipamentos, uma de especial atenção é a sua resolução, expressa em Megapixels. Como explicado anteriormente, quanto maior a resolução das imagens, melhor será a qualidade destas. Porém, a desvantagem é que imagens com alta resolução produzem arquivos digitais grandes, ocupando muito "espaço" na memória dos computadores, o que pode dificultar a sua performance, principalmente em apresentações com recurso de multimídia. Desta forma, o ideal é obter imagens de forma simples e rápida com qualidade satisfatória e tamanho em bytes mínimo para as diversas finalidades possiveis.

As câmeras digitais têm sido utilizadas desde meados da década de 90, porém, estas apresentavam diversas desvantagens como: baixa resolução, alto custo e necessidade de conhecimento técnico específico $^{29}$. Desta forma, a utilização deste recurso para fotografia clínica em Ortodontia despertou pouco interesse por parte dos profissionais ${ }^{14,26}$.

Com a evolução tecnológica das câmeras digitais, a qualidade das imagens geradas melhorou de forma surpreendente e com a queda acentuada dos preços, a relação custo-benefício deste sistema mostra-se, atualmente, bastante competitiva ${ }^{7}$. Além disso, a evolução destas câmeras possibilitou a existência de uma gama de variedades de equipamentos de diferentes marcas, modelos, características e preço. 
Se por um lado o aumento na oferta de sistemas fotográficos digitais permitiu às pessoas melhores opções, devido a essa ampla diversidade de câmeras fotográficas digitais disponíveis no mercado, a escolha mais acertada deste equipamento para realização de fotografias clínicas em Ortodontia tornou-se difícil e, de alguma maneira, duvidosa.

Dentre as diversas características das câmeras fotográficas digitais, uma das mais importantes é a sua resolução. Como descrito anteriormente, a resolução está diretamente relacionada com a qualidade final das imagens obtidas e vai depender da capacidade do CCD (charge coupled device) da câmera em capturar pixels ${ }^{9-12,14,27}$. Este dispositivo eletrônico desempenha papel similar aos filmes fotográficos convencionais, formar a imagem. Porém, enquanto no primeiro o material sensível à luz são substâncias à base de cristais de prata, no CCD os elementos sensíveis são chamados de fotodiodos (ou photosites) e cada um desses correspondem a cada pixel que em conjunto irão formar a imagem digital $^{31}$. Por isso, quanto maior a capacidade do CCD da câmera, maior quantidade de pixels por esta será capturada, gerando imagens muito mais ricas em detalhes e com cores mais fiéis. Como a câmara digital informa o número de pixels na horizontal e na vertical, a resolução da imagem é, por definição, o produto do número de pixels na horizontal pelo número de pixels na vertical ${ }^{10-12,23,30,31}$. Por exemplo, uma imagem que possui 1.600 pixels na horizontal por 1.200 pixels na vertical possuirá uma resolução de aproximadamente 2 milhões de pixels (1.600 x 1.200). Como o número total de pixels das imagens digitais é grande, torna-se comum que a resolução seja expressa em Megapixels (MP), termo em que o prefixo "mega" representa "milhões" (ou seja, em milhões de pixels) ${ }^{31}$.

A maioria das câmeras fotográficas digitais disponíveis no mercado possuem o CCD com resolução que varia de 3 a 6 MP. É importante explicitar que a escolha da resolução deve estar diretamente relacionada com o objetivo final das imagens, obedecendo à regra básica descrita anteriormente: a resolução utilizada de entrada (input) deve estar compatível com a finalidade da utilização da imagem ou saída (output) ${ }^{30}$. Em outras palavras, a resolução das fotografias realizadas com uma câmera digital deve estar condizente com o objetivo final da imagem: monitor, projetor de multimídia ou impressora. Com o objetivo de obter imagens com qualidade satisfatória e tamanho em bytes mínimo de forma a não ocupar muito espaço na memória do computador e não dificultar a performance das apresentações no Microsoft $\AA$ PowerPoint ${ }^{\circledR}$ (Redmond, WA, USA).

Como descrito anteriormente, a resolução média da maioria dos monitores e projetores de multimídia disponíveis no mercado é de aproximadamente $1.024 \times 768$ pixels $(0,8 \mathrm{MP})$, podendo chegar a $1.600 \times 1.200$ pixels (2 MP). Dessa forma, sugere-se a resolução de $1 \mathrm{MP}$ (1.280 x 960 pixels) para as fotografias com a finalidade de serem visualizadas em monitores e projetores de multimídia. Essa resolução proporcionaria resolução e definição adequadas, pois ao se inserir uma imagem durante a preparação de apresentações no programa Microsoft $®$ PowerPoint $\AA$ (Redmond, WA, USA), essa apresentaria o tamanho um pouco maior do que a tela disponível. Com isso, não seria necessário, aumentar (esticar) a imagem o que poderia resultar em perda de definição. Os exemplos descritos para ilustrar a utilização de scanners são plenamente aplicáveis, caso uma imagem de 1 MP seja inserida na tela do computador no programa Microsoft $®$ PowerPoint $®$ (Redmond, WA, USA), esta apresentará resolução e definição adequadas (Fig. 18) com uma relação qualidade - consumo de memória apropriada. Ao se inserir a mesma imagem com a resolução de $4 \mathrm{MP}$, por exemplo, embora esta possua uma resolução de entrada (input) maior, a resolução de ambas será a mesma pois a resolução de saída (output) é a tela do computador. A diferença, entre as duas é que a imagem com $4 \mathrm{MP}$ possui o tamanho muito maior (Fig. 19), necessitando ser diminuída (comprimida) para se adequar ao espaço da tela. 
Durante esse processo, a resolução não é alterada e nem o tamanho em bytes da imagem, o que é uma grande desvantagem, pois o arquivo final ocupara muito espaço em bytes, o que pode prejudicar a performance das apresentações no Microsoft $\AA$ PowerPoint ${ }^{\circledR}$ (Redmond, WA, USA).

Com a finalidade de utilizar as imagens digitais obtidas por meio de câmeras digitais, para impressão na forma de documentos pessoais, painéis científicos ou artigos científicos, a resolução da imagem estará relacionada com o tamanho máximo que a imagem pode ser ampliada em papel com qualidade fotográfica ${ }^{12,19}$.

Como as imagens obtidas por meio de câmeras digitais informam a quantidade de pixels presentes na horizontal e na vertical, por exemplo, $1.280 \times 960$ pixels (1 MP) e 2.048 x 1.536 pixels (3 MP), elas precisam ser convertidas em DPI (dots per inch, ou pontos por polegada) para serem impressas, pois este é o padrão utilizado pelas impressoras. $\mathrm{Na}$ verdade não existe uma relação direta entre a resolução das fotografias digitais e a quantidade de DPI que esta apresenta, pois como as imagens obtidas com câmeras digitais serão visualizadas em telas de computadores, estas apresentam 72 PPI, em média (resolução de tela de computador). A diferença é que resoluções maiores produzem imagens gigantescas em 72 PPI (Fig. 19) e quando convertidas para qualquer programa

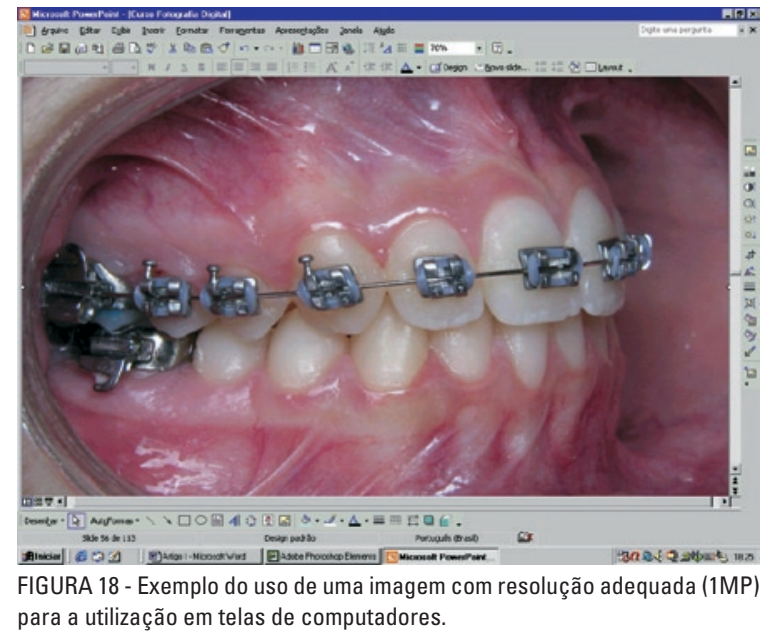

de edição de imagens para impressão em 300 DPI essa imagem diminui drasticamente se adequando aos 300 pontos por polegada linear. Dessa forma, resoluções maiores, como $2.400 \times 1.600$ pixels (4 MP), por exemplo, poderão ser impressas em tamanhos maiores e resoluções menores, $1.280 \mathrm{x}$ 960 pixels (1 MP), por exemplo, terão um limite de tamanho para impressão com qualidade bastante reduzido.

Então, como saber qual o limite máximo de impressão para uma determinada fotografia digital? Para calcular o tamanho de impressão a partir de dimensões de pixels, deve-se dividir os valores das dimensões horizontais e verticais (largura x comprimento) dos pixels pela resolução em DPI efetiva que se deseja trabalhar ${ }^{16,19,25}$. Como a resolução para impressão de escolha é 300 DPI, dividem-se os valores por 300 DPI e será obtido o tamanho máximo em polegadas (largura $\mathrm{x}$ comprimento) para impressão, enquanto que para imagens que serão visualizadas na tela do computador dividem-se os valores por 72 PPI. Por exemplo, uma imagem com 1.280 x 960 pixels (1 MP), poderá ser impressa a um tamanho máximo de $4,2$ " x 3,2" (10 x $8 \mathrm{~cm})$ pois 1.280/300 é igual a 4,2 polegadas e 960/300 é igual a 3,2"19. Quanto maior a resolução da imagem, esta poderá ser impressa com um tamanho maior. Por exemplo, uma imagem com 2.400 x 1.600 pixels (4 MP), poderá

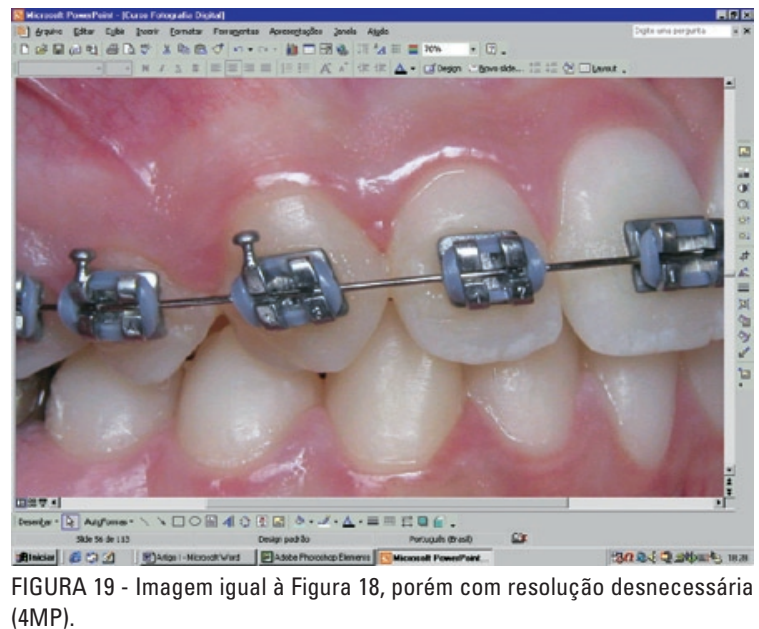

FIGURA 19 - Imagem igual à Figura 18, porém com resolução desnecessária (4MP). 
ser impressa a um tamanho máximo de 8" x 5,3" $(20 \times 13 \mathrm{~cm})$ pois $2.400 / 300$ é igual a 8 polegadas e 1.600/300 é igual a 5,3"19. Com o objetivo de simplificar a relação entre a resolução e o tamanho máximo de impressão com qualidade fotográfica (300 DPI), a tabela 3 possui as resoluções mais comumente utilizadas pelas diversas câmeras disponíveis no mercado.

Outra forma para converter a resolução em Megapixels para DPI e encontrar qual o limite máximo de impressão para uma determinada fotografia digital é a utilização de programas de edição de imagens. Por exemplo, os usuários dos programas Adobe ${ }^{\circledR}$ Photoshop ${ }^{\circledR}$ e Adobe ${ }^{\circledR}$ Photoshop ${ }^{\circledR}$ Elements (Seattle, WA, USA) podem realizar tal conversão de maneira simples e rápida ${ }^{18}$. Com o objetivo de simplificar esse procedimento acompanhe o exemplo, passo a passo, a seguir: (1) na tela deste programa com uma imagem digital disponível seleciona-se a opção "Image" no canto superior da tela e posteriormente os ícones "Resize" e "Image Size"; (2) uma janela irá aparecer indicando o tamanho da imagem em pixels (Fig. 20), que nesse exemplo é de 1.600 x 1.200 pixels (2MP) e a resolução no canto inferior que é de $72 \mathrm{PPI}$, pois como já foi explicado, as câmeras digitais capturam imagens com tal resolução com a finalidade de serem utilizadas em monitores. Observem que o tamanho máximo para a utilização dessa imagem é enorme
(56 x $42 \mathrm{~cm}$ ). Em seguida, ao mudar a resolução de 72 PPI para a desejada, que no nosso caso será de 300 DPI, a imagem diminui drasticamente para o limite de 13,5 x $10 \mathrm{~cm}$ (Fig. 21) para se adequar aos 300 pontos por polegada (resultado condizente com a tabela 3). Para essa finalidade, deve-se sempre desmarcar a opção "Resample Image" no canto inferior da tela (Fig. 21), pois caso isso não seja feito, o tamanho físico da imagem não será alterado e esta sofrerá interpolação para aumentar a resolução artificialmente ${ }^{18}$. Por outro lado, a opção "Constrain Proportions" deve sempre estar selecionada para que as proporções em relação ao tamanho sejam mantidas ${ }^{18}$.

Desta forma, para imprimir as imagens digitais obtidas por meio de câmeras fotográficas digitais com qualidade fotográfica, deve-se utilizar uma determinada resolução condizente com o tamanho final de impressão (Tab. 3). Como o tamanho de imagem utilizado pela maioria das nossas necessidades ortodônticas de rotina, geralmente, não ultrapassa o tamanho de $10 \times 15 \mathrm{~cm}$, como por exemplo, impressão de relatórios, confecção de banners, revelação em laboratórios especializados e utilização em publicações científicas, sugere-se que a resolução de $2.048 \times 1.536$ pixels (3 MP) seja utilizada para todas essas finalidades. Embora a utilização da resolução de 2 MP também proporcione impressões com qualidade fotográfica no

Tabela 3 - Relação entre a resolução das fotografias digitais e sua máxima ampliação para utilização nas telas de computadores e impressão com qualidade fotográfica: Adaptado de MEGAPIXEL, 2003.

\begin{tabular}{c|c|c|c|}
\hline Câmera & $\begin{array}{c}\text { Imagem no monitor } \\
72 \text { PPI }\end{array}$ & $\begin{array}{c}\text { Imagem impressa } \\
\text { 300 DPI }\end{array}$ \\
\hline Resolução & Tamanho da imagem & Tamanho da imagem \\
\hline $800 \times 600-0,5 \mathrm{MP}$ & $11^{\prime \prime} \times 8^{\prime \prime}$ ou $28 \times 21 \mathrm{~cm}$ & $2,6^{\prime \prime} \times 2 "$ ou $6,7 \times 5 \mathrm{~cm}$ \\
\hline $1.024 \times 768-0,8 \mathrm{MP}$ & $14^{\prime \prime} \times 10^{\prime \prime}$ ou $36 \times 27 \mathrm{~cm}$ & $3,4^{\prime \prime} \times 2,5^{\prime \prime}$ ou $8,6 \times 6,5 \mathrm{~cm}$ \\
$1.280 \times 960-1 \mathrm{MP}$ & $17^{\prime \prime} \times 13^{\prime \prime}$ ou $45 \times 33 \mathrm{~cm}$ & $4,2^{\prime \prime} \times 3,2^{\prime \prime}$ ou $10 \times 8 \mathrm{~cm}$ \\
\hline $1.600 \times 1.200-2 \mathrm{MP}$ & $22^{\prime \prime} \times 16^{\prime \prime}$ ou $56 \times 42 \mathrm{~cm}$ & $5,3^{\prime \prime} \times 44^{\prime \prime}$ ou $13,5 \times 10 \mathrm{~cm}$ \\
$2.048 \times 1.536-3 \mathrm{MP}$ & $28^{\prime \prime} \times 21^{\prime \prime}$ ou $72 \times 54 \mathrm{~cm}$ & $6,8^{\prime \prime} \times 5^{\prime \prime}$ ou $17 \times 13 \mathrm{~cm}$ \\
$2.400 \times 1.600-4 \mathrm{MP}$ & $33^{\prime \prime} \times 22^{\prime \prime}$ ou $84 \times 56 \mathrm{~cm}$ & $8^{\prime \prime} \times 5,3^{\prime \prime}$ ou $20 \times 13,5 \mathrm{~cm}$ \\
$2.560 \times 1.920-5 \mathrm{MP}$ & $35^{\prime \prime} \times 26^{\prime \prime}$ ou $89 \times 66 \mathrm{~cm}$ & $8,5^{\prime \prime} \times 6,4^{\prime \prime}$ ou $21,6 \times 16 \mathrm{~cm}$ \\
$3.000 \times 2.000-6 \mathrm{MP}$ & $41^{\prime \prime} \times 27^{\prime \prime}$ ou $104 \times 70 \mathrm{~cm}$ & $10^{\prime \prime} \times 6,6^{\prime \prime}$ ou $25,4 \times 17 \mathrm{~cm}$
\end{tabular}




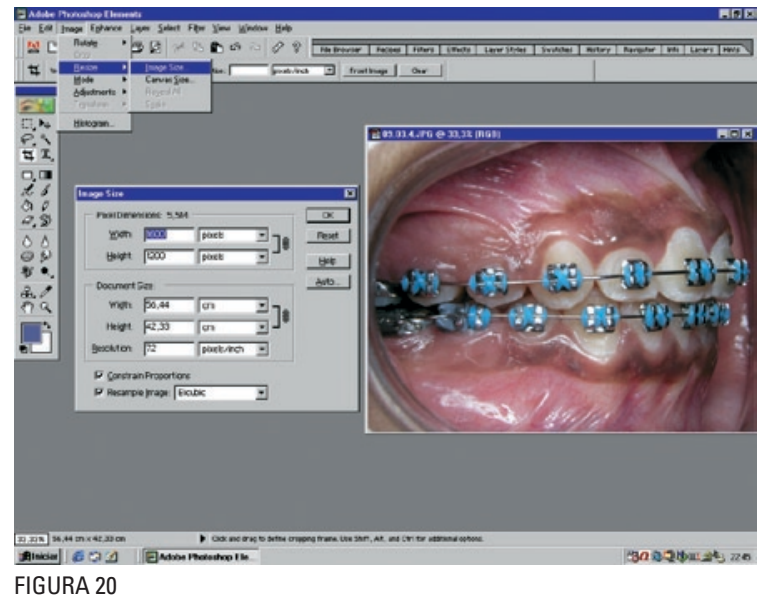

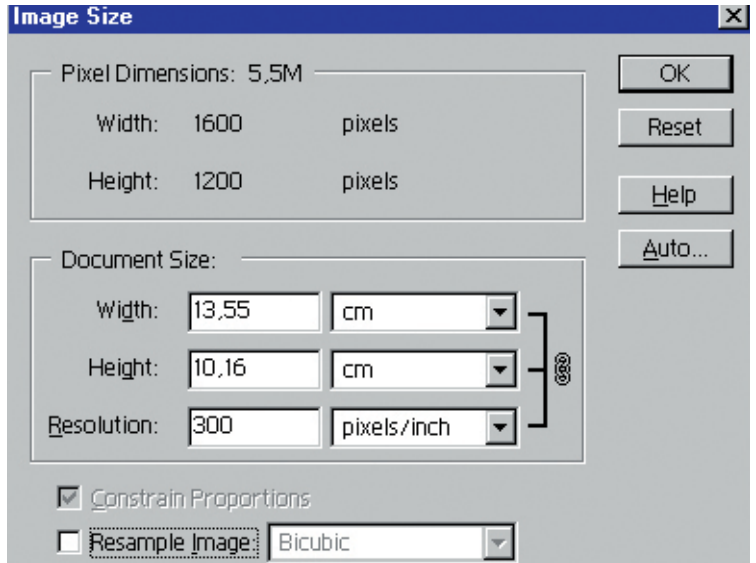

FIGURA 21

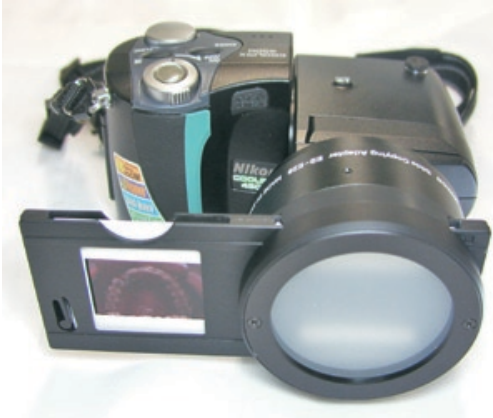

FIGURA 22

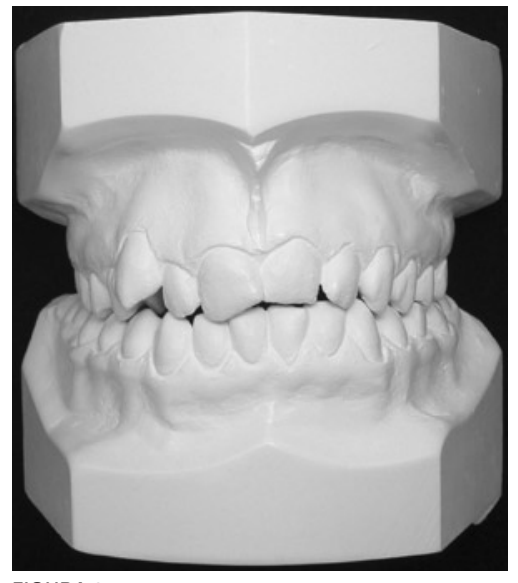

FIGURA 25

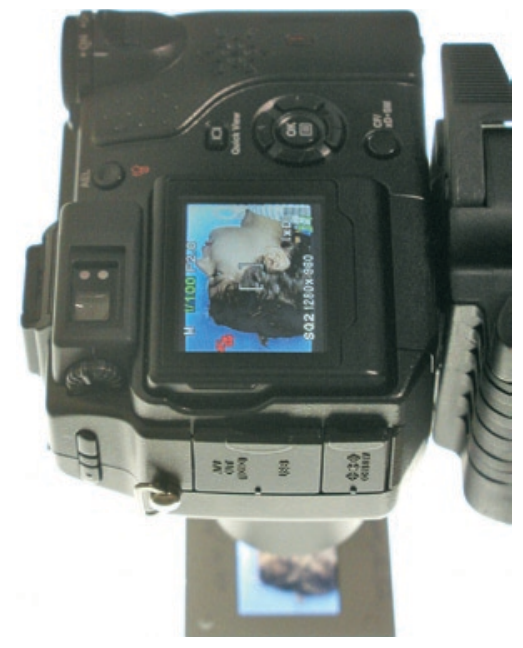

FIGURA 23

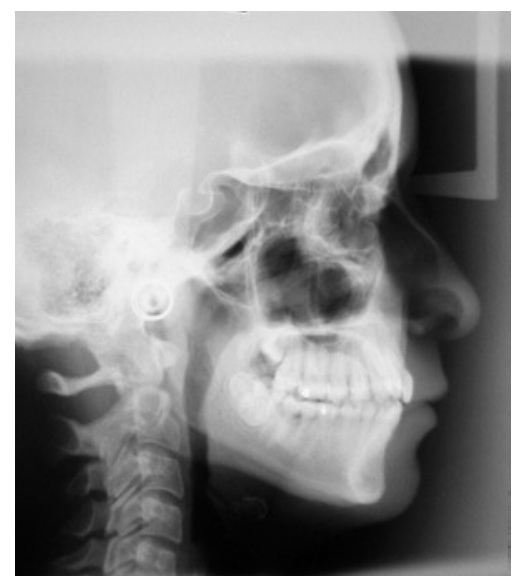

FIGURA 26

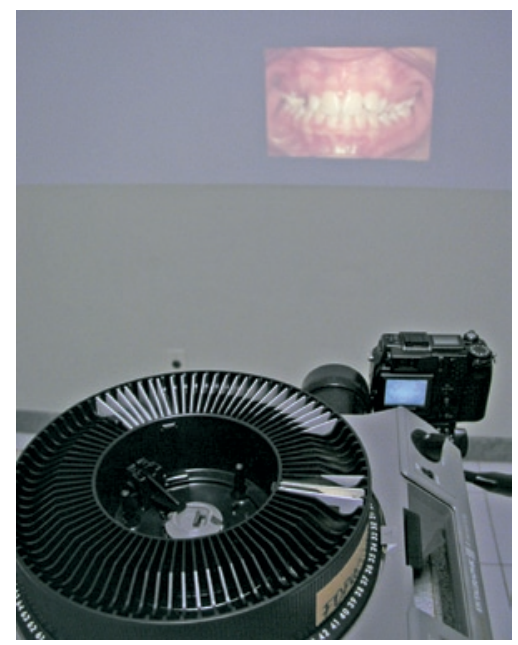

FIGURA 24

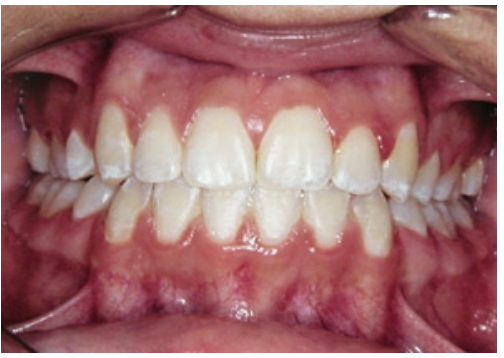

FIGURA 27 


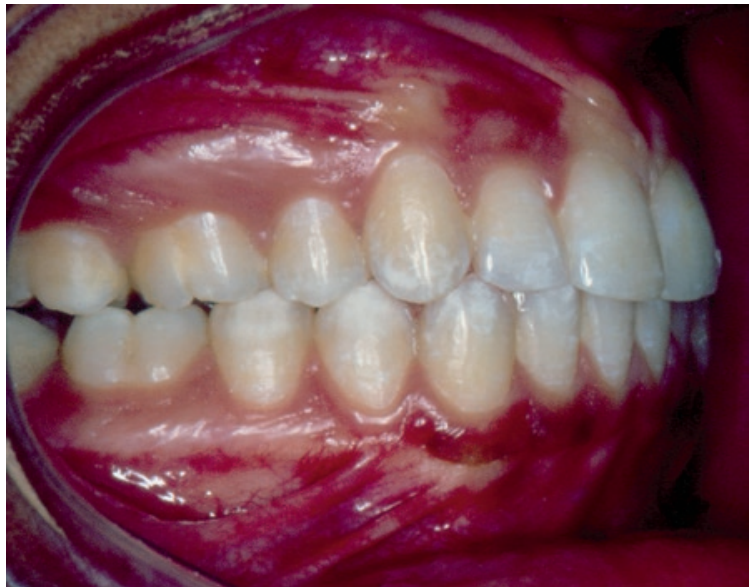

FIGURA 28 - Slide digitalizado com um scanner.

tamanho 10 x $15 \mathrm{~cm}$, a opção por $3 \mathrm{MP}$ viabiliza uma margem de segurança para a realização de pequenas edições nas imagens, como a ferramenta de corte. Naquelas situações em que o tamanho final da imagem seja maior do que $17 \times 13 \mathrm{~cm}$ (padrão para $3 \mathrm{MP}$ ), pode-se utilizar resoluções maiores para atingir o tamanho final necessário.

Com respeito ao formato de arquivo, sugerese que as imagens digitais adquiridas por meio de câmeras fotográficas digitais, sejam do tipo JPEG pelas razões discutidas anteriormente.

Aspecto que deve ser levado em consideração e que já foi discutido, é que como as imagens obtidas por meio de câmeras fotográficas digitais serão visualizadas em monitores de computador, com a finalidade de serem armazenadas neste ou de serem enviadas para impressão, uma perfeita calibração dos monitores deve ser realizada para minimizar alterações inoportunas na qualidade final das imagens.

A versatilidade das câmeras fotográficas digitais é surpreendente. Mais uma grande vantagem desses equipamentos é de ser um excelente recurso para realizar a digitalização de fotografias analógicas, radiografias, modelos de estudo e imagens de livros, substituindo o uso dos scanners. A Nikon (Nikon Inc., Melville, NY, USA) lançou no mercado um adaptador para algumas câmeras digitais da linha Coolpix, o Nikon ES-E28 Slide, que serve

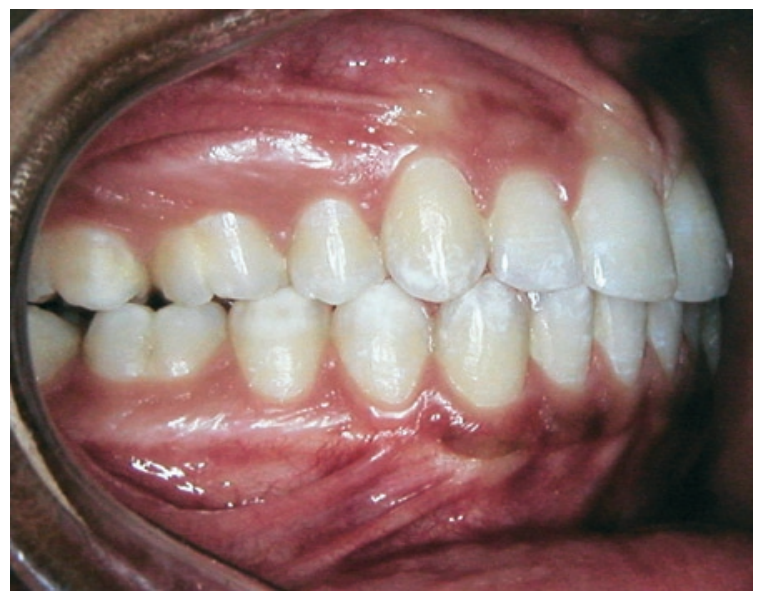

FIGURA 29 - Mesmo slide da FIG. 28, porém digitalizado com uma câmera digital.

para digitalizar slides (Fig. 22). Uma outra opção é posicionar radiografias e slides sobre um negatoscópio (Fig. 23) ou projetá-los em uma tela (Fig. 24) e fotografá-los com a câmera digital, assim todos os documentos analógicos (slides e radiografias) serão digitalizados (imagem digital). Por exemplo, a figura 25 mostra a imagem de um modelo de estudo adquirida por meio de uma câmera digital, enquanto as figuras 26 e 27 ilustram uma radiografia e um slide, respectivamente, digitalizados seguindo os critérios da figura 23.

Esta vantagem é uma excelente opção para aqueles profissionais que possuem um número expressivo de documentações e pretendem transformá-las em imagens digitais. Na maioria das vezes, o processo realizado com utilização de scanners é lento e o custo desses equipamentos, de alta qualidade, é alto. As câmeras digitais podem realizar o mesmo processo mais rapidamente e obter resultados satisfatórios. A figura 28 ilustra a imagem de um slide digitalizada por meio de um scanner com resolução de 300 DPI associado à escala de 400\%. Ao analisar a figura 29, imagem do mesmo slide, digitalizada com uma câmera fotográfica digital seguindo as recomendações anteriores, conclui-se que a qualidade proporcionada por esse processo encontra-se plenamente aplicável.

Fato de grande relevância que deve ser explicitado é que a resolução em Megapixels das câmeras 
digitais, que é muitas vezes alvo de propaganda por parte dos fabricantes, é somente uma dentre as várias características que serão responsáveis pela qualidade final da imagem digital. Embora o foco principal deste artigo seja a resolução em pixels, esta característica está mais relacionada com o tamanho máximo de impressão que uma imagem digital possa ser submetida do que com a qualidade propriamente dita. Além disso, a discussão atual gira em torno do seguinte questionamento: será que imagens com mais resolução (em Megapixels) proporciona sempre mais qualidade? A razão principal dessa dúvida é porque algumas câmeras digitais recém lançadas no mercado com resolução de $8 \mathrm{MP}$ estão apresentando qualidade inferior aos equipamentos anteriores com $5 \mathrm{MP}$. $\mathrm{Na}$ verdade, alguns fabricantes obrigados pela "febre" dos Megapixels lançam novos equipamentos no mercado sem a realização de testes adequados. Além da quantidade de pixels presente nas imagens, outros fatores irão influenciar a qualidade final das fotografias como a forma, o tamanho e a diagramação dos pixels no CCD da câmera.

Conclui-se que para que fotografias digitais sejam realizadas com qualidade, deve-se lançar mão de equipamentos adequados, com resoluções satisfatórias, objetivas (conjunto de lentes) com excelente qualidade óptica e um sistema de iluminação ideal.

\section{CRIANDO UM BANCO DE IMAGENS}

Embora o objetivo ideal seja digitalizar imagens por meio de um processo simples e rápido e que possua a melhor relação qualidade - consumo de memória, em alguns casos, os profissionais, as clínicas e centros de ensino e pesquisa em Odontologia que desejam utilizar esse recurso não têm certeza de qual será a finalidade das imagens digitais. Para esses casos, sugere-se que um banco de imagens seja criado.

Nessa situação, deve-se obter as imagens por meio de um scanner ou câmera fotográfica digital com a resolução necessária para o objetivo que precise de maior resolução, como a utilização das imagens para artigos científicos. Por isso, durante a utilização dos scanners, deve-se utilizar a resolução de 300 DPI e uma escala de 1:4 ou 400\% ou a resolução de 1.200 DPI a uma escala de 1:1 ou 100\% (segundo as sugestões descritas anteriormente). Em relação às imagens obtidas por meio de câmeras digitais, sugere-se que a resolução de $2.048 \times 1.536$ pixels (3 MP) seja utilizada. Desta forma, pode-se obter qualidade fotográfica de impressão em imagens com tamanho de 10 x 15 $\mathrm{cm}$, para ambos métodos, scanner ou câmera, favorecendo a utilização dessas para a maioria das necessidades ortodônticas de rotina, descritas anteriormente, incluindo publicações científicas.

Embora imagens com alta resolução (Fig. 19) não apresentem nenhuma vantagem em relação às imagens de resolução adequada (Fig. 18) quando da utilização para visualização em monitores e em projetores multimídia, a alta resolução propicia a seleção de pequenas partes das imagens para a mesma finalidade e com resolução adequada. A figura 30, por exemplo, possui $4 \mathrm{MP}$ e a utilização dessa imagem em apresentações no Microsoft ${ }^{\circledR}$ PowerPoint ${ }^{\circ}$ (Redmond, WA, USA) resultaria em uma imagem muito grande (como na Fig. 19) e a desvantagem de um arquivo carregado. Porém, como a resolução é alta, é possível selecionar áreas menores da imagem, como o retângulo em vermelho, com resolução e definição satisfatória (1 MP) para ser utilizada em monitores e projeções de multimídia (Fig. 31). Portanto, quanto maior a resolução original da imagem, menor poderá ser a área selecionada para ser utilizada com resoluções menores, porém condizentes com a finalidade desejada.

Vale ressaltar que as imagens obtidas com resoluções altas (como as sugeridas anteriormente) podem ser facilmente alteradas, em programas de edição de imagens como o Adobe ${ }^{\circledR}$ Photoshop ${ }^{\circledR}$ (Seattle, WA, USA) e a maioria dos programas que acompanham os scanners e câmeras digitais, e a resolução diminuída para as determinadas necessidades. Por exemplo, para utilizar as imagens do banco de imagens em apresentações do Microsoft $₫$ PowerPoint $₫$ (Redmond, WA, USA) que utilizam resoluções mais 


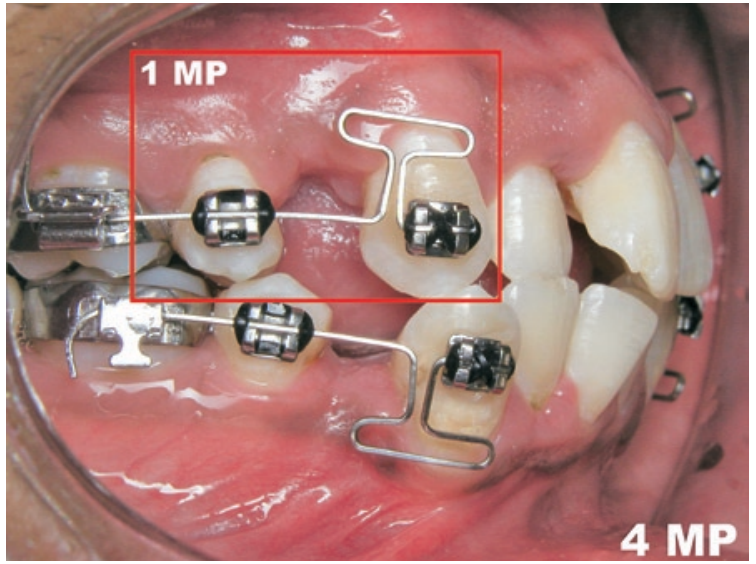

FIGURA 30

baixas (1.280 x 960 pixels - 1 MP), como os monitores e projetores de multimídia, diminui-se a resolução para conseguir uma relação qualidade - consumo de memória mais adequada. Porém, o oposto não é verdade, caso uma imagem seja digitalizada em baixa resolução, esta dificilmente poderá ser utilizada para algumas finalidades que necessitem alta resolução ${ }^{3,24}$. Por exemplo, uma imagem obtida por meio de uma câmera digital com resolução de 1.280 x 960 pixels (1 MP) que precise ser impressa em alta resolução para confecção de um painel científico em um tamanho de $17 \times 13 \mathrm{~cm}$ (padrão para imagens com resolução de $3 \mathrm{MP}$ ) não apresentará qualidade suficiente. Nessas situações pode-se lançar mão do processo conhecido como interpolação (explicado anteriormente), ou seja, o aumento da resolução de forma artificial. Para a realização desse recurso com o programa Adobe ${ }^{\circledR}$ Photoshop ${ }^{\circledR}$ (Seattle, WA, USA) deve-se realizar o mesmo procedimento descrito nas figuras 20 e 21, porém a opção "Resample Image" no canto inferior da tela (Fig. 21), deve ser selecionada. Com isso, pixels artificiais serão criados e a resolução aumentada. Isso não significa que imagens com baixas resoluções possam ser transformadas em altas resoluções, pois, o fenômeno da interpolação deve ser utilizado para pequenos detalhes e com muito critério e moderação.

$\mathrm{O}$ último aspecto a ser abordado diz respeito ao armazenamento das imagens digitais. $\mathrm{O}$ processo de

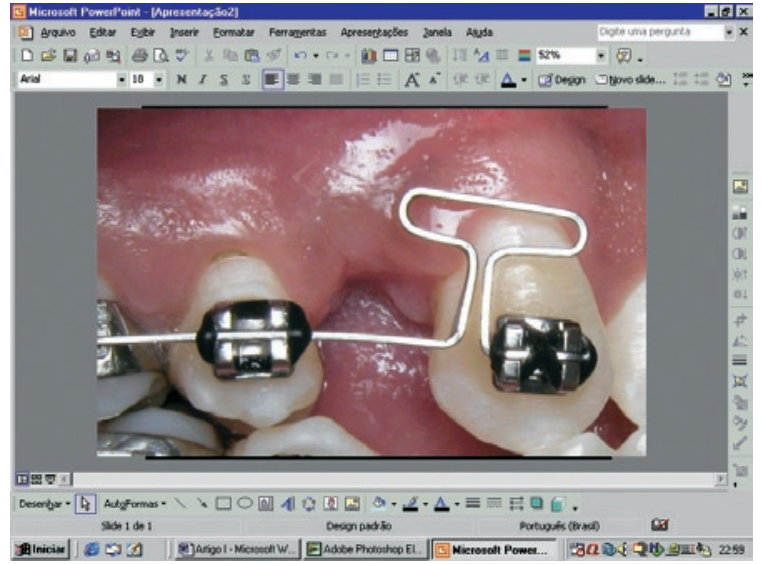

FIGURA 31

armazenamento consiste em definir o local no qual as imagens obtidas serão armazenadas. Enquanto diversas variáveis devem ser controladas para o correto armazenamento da documentação composta por fotografias analógicas como temperatura, quantidade de luz, umidade relativa e qualidade do ar, alguns cuidados também devem ser seguidos para a correta manutenção das imagens digitais ${ }^{33}$. Da mesma forma que a fotografia analógica está sujeita a deterioração por fungos, as imagens armazenadas em computador podem ser destruídas por "vírus", ou qualquer tipo de dano físico que possa comprometer a integridade do computador. Por isso, é aconselhável que as imagens digitais sejam gravadas em outros locais ${ }^{14}$. Um excelente recurso é colocar todas as imagens em Compact Discs (CDs), ou selecionar as imagens de cada paciente para cada CD específico. Esta é uma forma simples, segura e de baixo custo para armazenar todas as imagens digitais. Como a tecnologia da informática está em constante evolução, mais uma opção para o armazenamento das imagens digitais são os Digital Video Discs (DVDs). Este novo recurso apresenta a excelente vantagem de armazenar cerca de sete vezes mais dados do que os CDs, são 4,7 GB de capacidade dos DVDs contra $700 \mathrm{MB}$ dos CDs. Em contrapartida, o custo atual ainda é alto, porém, é só uma questão de tempo para o acesso ser cada vez mais facilitado. 


\section{CONSIDERAÇÕES FINAIS}

A possibilidade de uso de imagens digitais é fruto dos avanços científicos e tecnológicos pelos quais a Ortodontia vem se beneficiando, desde a sua criação como especialidade odontológica. Este "novo" recurso permiti aos profissionais desta área utilizar recursos, antes inimagináveis, facilitando o diagnóstico das más oclusões, a comunicação entre profissionais, bem como com os pacientes, além de ser uma excelente ferramenta para a avaliação crítica prospectiva e retrospectiva da evolução e resultado do tratamento ortodôntico.

A revolução tecnológica, especificamente em relação à imagem digital, obriga os ortodontistas interessados em utilizar essa nova tecnologia a conhecer não somente a linguagem utilizada nessa área, mas também as principais formas de obtenção e utilização das imagens digitais.

Deve-se observar que estas recomendações para o processo de obtenção de imagens digitais são apenas sugestivas. Elas não foram comprovadas em pesquisa científica nem foram endossadas por qualquer corpo de normalização técnica. Contudo, elas podem servir como sugestão para os profissionais que pretendem utilizar essa "nova" tecnologia ou para uma discussão mais ampla envolvendo diretrizes para a obtenção de imagens digitais.

Com isso, o objetivo deste artigo foi realizar uma breve revisão da literatura sobre o assunto, com ênfase nos principais conceitos básicos, além de sugerir diretrizes para a obtenção de imagens digitais por meio da utilização de scanners e câmeras fotográficas digitais para diferentes finalidades. Desta forma, espera-se que esse artigo possa contribuir para o entendimento da linguagem utilizada nesse campo, simplificando a obtenção de imagens digitais seja por meio de scanners ou pela utilização de câmeras fotográficas digitais, sendo com isso, um ponto de partida para a entrada dos ortodontistas na era da imagem digital.

Enviado em: Dezembro de 2003 Revisado e aceito: Maio de 2004

\title{
How to easily acquire and use digital images: scanners and digital cameras
}

\begin{abstract}
The use of digital images is one of the fastest-growing new technologies in the contemporary society. The use of this new technology in Dentistry, and especially in Orthodontics, associated with the introduction of "Digital Photography" allows the clinician to acquire things ever imagined, facilitating the orthodontic diagnosis, improving the doctor/doctor and doctor/patient communication, illustrating scientific communications in speeches, conferences and articles, being thereby, an excellent tool for teaching and research. In order to take advantages of this new field, the orthodontic records including photographs, models and radiographs must be converted into digital images. Therefore, as we enter into the "digital world", the aim of this paper is to clarify some basic concepts regarding the digital imaging and try to answer the must common questions about this topic: How to convert digitally the orthodontic records with a scanner? How to acquire digital images with a digital camera? At what resolution in DPI (dot per inch) or in Megapixel (MP), file size and file format should the images have to fulfill my usual demands? At what resolution should the images have in order to be used in the computer monitor? And what resolution should the images be imported into presentation programs in order to be displayed in multimedia projectors? And at last, how to easily acquire digital images that will be used in scientific papers?
\end{abstract}

Key words: Image. Digital Image. Imaging in Orthodontics. 


\section{REFERÊNCIAS}

1. ALT, P. M.; NODA, K. Increasing display information content: an introduction. Disponível em: <http://www.research.ibm. com/journal/rd/423/alt.pdf>. Acesso em: 5 set. 2003.

2. ABELSON, M. N. Digital Imaging Update. Am J Orthod Dentofacial Orthop, St. Louis, v. 116, no. 5, p. 587-590, Nov. 1999.

3. ABELSON, M. N. Parameters for digital imaging. Part 1. Am J Orthod Dentofacial Orthop, St. Louis, v. 118 , no. 5 , p. 580 582, Nov. 2000.

4. ABELSON, M. N. Parameters for digital imaging. Part 2. Am J Orthod Dentofacial Orthop, St. Louis, v. 118, no. 6, p. 707711, Dec. 2000.

5. ASKEY, P. Learn: glossary: digital imaging: JPEG. Disponíve em: < http://www.dpreview.com/learn/Glossary/Digital_Imaging/JPEG_01.htm>. Acesso em: 5 set. 2003.

6. ASKEY, P. Learn: glossary: digital imaging: RAW image format Disponivel em: <http://www.dpreview.com/learn/Glossary/Digital_Imaging/RAW_Image_Format_01.htm>. Acesso em: 5 set. 2003.

7. BRANCO, S.; AZZI, T. Entrada para o mundo das digitais: fotografe melhor. São Paulo, n. 65, p. 32-47, 2002

8. BUSCH, D. D. Scanner para IBM - PC. Rio de Janeiro: Livros Técnicos e Científicos, 1993.

9. FIORELLI, G.; PUPILLI, E.; PATANE, B. Digital phtotography in the orthodontic practice. J Clin Orthod, Boulder, v. 32, no. 11 p. 651-656, Nov. 1998

10. FITTIPALDI, M. Por dentro da câmera digital. Guia prático digital: fotografe melhor, São Paulo, ano 7, n. 3, p. 14-25, 2003

11. GUIA prático digital: glossário. Fotografe Melhor, São Paulo, n. 3, p. 64-73, 2003

12. . GUIA prático digital: um mundo em evolução. Fotografe Melhor, São Paulo, n. 3, p. 10-13, 2003

13. HORNSTEIN, J. Scanner: digitalização de imagens. Rio de Janeiro: Ed. Campos, 1996.

14. HUTCHINSON, I.; IRELAND A. J.; STEPHENS, C. D. Digital cameras and orthodontics: an overview. Dent Update, Guildford v. 26, p. 144-149, May 1999

15. HUTCHINSON, I.; WILLIAMS, P. Digital cameras. Br J Orthod London, v. 26, no. 4, p. 326-331, Dec. 1999.

16. KENNEY, A. R.; CHAPMAN, S. Requisitos de resolução digital para textos: métodos para o estabelecimento de critérios de qualidade de imagem. Rio de Janeiro: Arquivo Nacional, 1997. Projeto conservação preventiva em bibliotecas e arquivos.
17. LOPES, A.; MACHADO, C.; VIEIRA, E.; GREGO, M. A hora do clique digital. Exame, São Paulo, n. 197, p. 52-78, ago. 2002

18. McCLELLAND, D. Photoshop 5 \& 5.5 Bíblia. São Paulo: Market Books, 1999

19 MEGAPIXEL. The relationship between megapixels and printed image size. Disponível em: < http://www.megapixel. net/html/issueindex.php?lang=en>. Acesso em: 19 set. 2003 .

20. PCTECHGUIDE. Digital imaging: scanners. Disponível em: <http://www.pctechguide.com/18scanners.htm>. Acesso em: 14 set. 2003

21. PCWEBOPEDIA. Color depth. Disponível em: <http://www. pcwebopedia.com/TERM/C/CMYK.html>. Acesso em: 10 set. 2003

22. PCWEBOPEDIA. True color. Disponível em: <http://www. pcwebopedia.com/TERM/T/true_color.html >. Acesso em: 10 set. 2003.

23. RAMALHO, J. Informática: foto digital. Belo Horizonte: [s.n.], 2003.

24. REGENNITTER, F. J. Planning considerations for digital conversion of $35 \mathrm{~mm}$ slides. Am J Orthod Dentofacial Orthop, St. Louis, v. 117, no. 1, p. 110-112, Sept. 2000

25. RITTO, A. K. Imaging in orthodontics: present and future. J Clin Orthod, Boulder, v. 36, n. 11, p. 619-625, Nov. 2002.

26. SANDLER, J.; MURRAY, A. Digital photography in orthodontics. Br J Orthod, London, v. 28, p. 197-201, Sept. 2001.

27. SANDLER, J.: MURRAY, A.: BEARN, D. Digital records in orthodontics. Dent Update, London, v. 29, p. 18-24, Jan./Feb. 2002.

28. SILVER, B. An introduction to digital image processing Cognex Corporation. Modular Vision Systems Division, 2003. Disponível em: < https://www.machinevisiononline.org/public /articles/cognex1.PDF>. Acesso em: 25 mar. 2003.

29. STEWART, M. B. Management \& Marketing. J Clin Orthod, Boulder, v. 29, no. 8, p. 509-515, Aug. 1995.

30. SWARTZ, M. L. Managing digital images. Am J Orthod Dentofacial Orthop, St. Louis, v. 118, no. 3, p. 354-358, Sept. 2000.

31. TRIGO, T. Equipamento fotográfico: teoria e prática. 2. ed. São Paulo: Senac, 2003

32. WALL, S.; KAZAHAYA, K.; BECKER, S. S.; BECKER, D. G. Thirty-five milimeter versus digital photography: comparison of photographic quality and clinical evaluation. Facial Plastic Surgery, New York, v. 15, no. 2, p. 101-109, 1999.

33. WATERS, D. J. Do microfilme à imagem digital: projeto conservação preventiva em bibliotecas e arquivos. Disponível em: <http://www.cpba.net>. Acesso em: 29 abr. 2003.
Endereço para correspondência

André Wilson Machado

Av. Dom José Gaspar, 500, prédio 46

Coração Eucarístico

Belo Horizonte - MG

E-mail: awmachado@bol.com.br 